\title{
Poverty traps across levels of aggregation
}

\author{
Dylan Fitz ${ }^{1} \cdot$ Shyam Gouri Suresh ${ }^{2}$
}

Received: 28 February 2021 / Accepted: 22 July 2021 / Published online: 2 September 2021

(c) The Author(s) 2021

\begin{abstract}
Poverty trap studies help explain the simultaneous escape from poverty by some households and regions alongside deep and persistent poverty elsewhere. However, researchers remain divided about how important poverty traps are in explaining the range of poverty dynamics observed in various contexts. We build a theoretical model that integrates micro-, meso-, and macro-level poverty traps, allowing us to analyze the ways in which multiple layers of poverty traps interact and reinforce each other. Through this simulation model, markets and institutions arise endogenously and help certain individuals escape poverty, while others remain persistently poor. In addition to one's own productivity and initial capital levels, we explore how individual opportunity and income can be heavily determined by market access and institutional factors beyond one's control. Using simulation results from controlled experiments, we can identify the role played by meso- and macro-conditions (that correspond to local markets and country-wide institutions, respectively) in helping individuals escape poverty. Our results suggest that even in a parsimonious model-with optimizing, forward-looking agents operating in a world with only one trap at each level-local and national context matters immensely and combines to determine individual opportunity in complex ways.
\end{abstract}

Keywords Poverty traps $\cdot$ Multiple equilibria $\cdot$ Economic growth

JEL Classification D31 - I32 - I38 - O15 - R23

$凶 \quad$ Shyam Gouri Suresh

shgourisuresh@davidson.edu

Dylan Fitz

dylan.b.fitz@lawrence.edu

1 Economics Department, Lawrence University, 711 E Boldt Way, Appleton, WI 54911, USA

2 Economics Department, Davidson College, Box 7123, Davidson, NC 28035, USA 


\section{Introduction}

While recent decades have seen approximately one billion people, escape poverty, certain countries, regions, and individuals remain poor generation after generation. Despite the overall decline in extreme poverty globally, the Economist notes that "the bad news is that poverty is becoming harder to tackle," since World Bank estimates find that extreme poverty recently increased in Sub-Saharan Africa as well as the Middle East and North Africa (Economist, 2018). As a result, future success is uncertain and it may become even more difficult to achieve similar reductions in poverty in the future. In many cases, persistently poor individuals reside in remote regions where they use low-return technologies, have limited access to markets (including input, output, or labor markets), and where ineffective or corrupt governments fail to provide essential public goods, ensure secure property rights, or overcome coordination failures. As a result, it is important to analyze the conditions under which chronic poverty persists and the ways in which individual factors, local context, and national policies combine to perpetuate poverty. In this paper, we construct a poverty trap model combining insights from micro-, meso-, and macro-poverty trap studies and then use data generated by this model to explore the causes of individual poverty. Our model is based upon intertemporal utility maximizing, forward-looking agents who choose either a low- or high-return agricultural technology (our micro-trap) in a context where markets arise endogenously (our meso-trap, which is escaped when individuals choose to become traders, thus providing improved local market access to their neighbors) and government policies are determined endogenously (our macro-trap, where the median voter determines the level of public goods provision which can become more broadly beneficial and inclusive). We find evidence of poverty traps that are highly dependent on neighborhood and country characteristics. This implies that policy should be tailored to specific contexts, potentially including cash transfers in some cases alongside improved market access or public goods provision in others. To tackle the full range of causes of poverty, however, multiple policies will be required.

Two recent reviews of the poverty trap literature draw very different conclusions, with Kraay and McKenzie (2014) finding that poverty traps are "rare" and Barrett et al. (2016) concluding that there is "overwhelming" evidence that poverty traps frequently occur, as described more below. As is clear from reading these surveys, the empirical identification of poverty traps is inherently difficult, with multiple potential equilibria pulling data away from unstable thresholds, limited panel data, and complex and evolving interactions between individuals, local context, and national policies. Agentbased models can help inform and overcome these three challenges. In particular, it is especially useful for modeling interactions between individuals, neighborhoods, and countries. These interactions clearly matter, but their complexity means that theoretical models are less developed. The complications that result from integrating these layers of analysis lend itself well to agent-based models. Rich, detailed simulation data allow for empirical analysis that is otherwise impossible with real-world data. Additionally, our model allows us to analyze the importance of focusing on single or multiple equilibrium poverty traps. For example, with a range of initial conditions in a common layered model, we are able to show how some countries exhibit single equilibrium poverty traps, others multiple equilibrium traps, and others no poverty trap at all. 
Our paper thus has two primary research questions. First, how do multiple layers of poverty traps (micro, meso, and macro) interact with and potentially reinforce each other? To answer this question, we build upon Barrett and Swallow's (2006) definition of fractal poverty traps and develop a layered agent-based model. Our model has a poverty trap built into each level of analysis and endogenously determines which poverty traps are overcome in which contexts. Second, using data generated by our model, we ask how individual poverty depends on not only micro, but also meso- and macro-characteristics.

Our model highlights fractal poverty traps in order to analyze how multiple layers of poverty traps interact with and possibly reinforce each other. Barrett and Swallow (2006) develop an insightful informal model that we expand upon by formalizing each level of aggregation, where both single and multiple equilibrium poverty traps can coexist simultaneously at multiple levels of aggregation. We are interested in the welfare of individuals within households, but they make economic decisions within a context determined by larger meso- and macro-processes, and many of these factors evolve endogenously before further impacting individuals.

At the micro-level, we model individual poverty traps as occurring through lumpy production technologies, as individual farmers can use either a low-return technology or a high-return technology that requires a large fixed cost.

The meso-level is described by Barrett and Swallow (2006) as "communities, groups, networks, and local jurisdictions," and these factors can influence poverty through coordination, cooperation, local public goods, and markets. Our meso-level poverty trap focuses on the endogenous appearance of traders, who give up production in order to transport goods from other producers to markets while earning income through transport fees. In our model, the multiple equilibria include either the failure of any traders to arise (either because nobody can afford to become a trader or because there is not sufficient demand due to geographic clusters of subsistence agriculture) or the existence of a trader that improves market access through mutually beneficial contracts.

At the macro-level, we focus on the endogenous determination of macro-economic policy. A growing literature indicates that institutions are a fundamental cause of wealth and poverty across nations and a potential macro-level poverty trap (Acemoglu et al. 2001, 2005). The tax rate is chosen by the median voter, and the revenue is then used to provide a public good, which we model as a reduction in the cost of adopting the high-return technology. At the two extremes, a country may choose either low tax rates and low public goods provision or higher tax rates and high public goods provision. In the former, the government has little revenue and low public goods provision, meaning that only wealthy households are able to afford technology adoption and unequal opportunities persist. In the latter, higher taxes provide higher revenues and public goods provision, which makes the high-return technology accessible to more citizens.

For a given distribution of agents with fixed productivity and initial capital levels, households endogenously invest through time, markets arise endogenously through the decision of some agents to become traders, and voting decisions endogenously determine public goods provision. We then use our model to analyze our second research question, exploring the ways in which individual poverty is influenced by meso- and 
macro-contexts. To explore this question, we use our model to generate data in four scenarios: the baseline model described above, a situation where no traders are allowed to arise (meso-trap forced), a situation with no public goods provision (macro-trap forced), and one without markets or public goods (both traps enforced). Focusing on individual outcomes, we show that individual poverty traps depend on a range of exogenous (to the individual) factors. First, individuals with high productivity (capturing, for example, land quality) transition to the high-return technology in any scenario. Second, individuals with mid-range productivity levels fail to escape poverty when neither the meso- nor macro-trap can be overcome, but might do so when these traps are overcome due to neighborhood or country characteristics. We define this range as the geographic poverty trap and highlight the ways in which otherwise similar individuals may end up in very different equilibria based on context. We find that multiple equilibrium traps can appear in some layers of our model, while single equilibrium traps arise in others. Third, below a certain level of individual productivity, even the breaking of the meso- and macro-level traps is insufficient to help individuals escape poverty.

\section{Poverty trap literature}

The growing poverty trap literature provides valuable insights into the causes of poverty, developing a range of theoretical insights explaining why poverty falls in certain cases while persisting in others. ${ }^{1}$ However, debates remain about the importance of poverty traps and the strength of the empirical evidence verifying their existence. In a recent survey of the literature, Kraay and McKenzie (2014) conclude that poverty traps "are rare and largely limited to remote or otherwise disadvantaged areas" (p. 129), such as rural areas of South Africa (Adato et al. 2006) as well as Kenya and Madagascar (Barrett et al. 2006). In contrast, Barrett et al. (2016) argue that existing research provides "overwhelming evidence that poverty traps exist" (p. 321). Both surveys highlight a range of theoretical and empirical studies, including ones that focus on micro-, meso-, and macro-poverty traps. Even while creating as simple a layered poverty trap model as possible, we find that context matters immensely and, in many cases, largely determines individual opportunity and outcomes.

There are several reasons why similar surveys of the poverty trap literature produce such different conclusions. First, definitions of poverty traps differ. A useful definition is provided by Barrett et al. (2019b), who state that "the essence of a poverty trap is that equilibrium behavior leads predictably to expected poverty indefinitely, given preferences and the constraints and incentives an agent faces, including the set of markets and technologies (un)available to her" (p. 5). Within this framework, however, some authors focus only on multiple equilibrium poverty traps, while others additionally

\footnotetext{
1 Dynamic poverty trap models illustrate how initial conditions impede productivity, savings, and investment (see, for example, Galor and Zeira 1993; Bowles et al. 2016). A wide range of models provide theoretical justifications for the existence of poverty traps, including ones based on nutrition (Dasgupta and Debraj 1986), coordination failures (Rosenstein-Rodan 1943; Murphy et al. 1989), fixed capital investments (Banerjee and Newman 1993; Aghion and Bolton 1997; Carter and Barrett 2006; Barrett and Carter 2013), and lumpy human capital investments (Basu and Van 1998).
} 
analyze single equilibria in which all individuals remain poor without an opportunity to reach a higher, non-poor equilibrium. With multiple equilibrium poverty traps, a threshold separates those that converge to the poverty steady state from those that grow toward a non-poor steady state. For example, Kraay and McKenzie (2014) only focus on multiple equilibria in their survey. ${ }^{2}$ Given the existence of a threshold separating the two steady states, a short-term transfer can move households beyond the threshold and allow them to begin accumulating more wealth independently, thus providing long-run benefits without requiring further assistance (Rosenstein-Rodan 1943; Murphy et al. 1989; Sachs 2006). Thus, these multiple equilibrium poverty traps produce two important implications: initial conditions matter and one-time policy interventions can produce long-run benefits.

However, many households remain trapped in poverty even without the existence of a potential high-income steady state sitting just beyond their reach. This idea is captured by single equilibrium poverty traps, which exist when there is only a single steady state in which all individuals remain poor. In these contexts, short-term transfers will only provide short-term relief from poverty. Rather than being explained only by initial conditions, single equilibrium poverty traps place greater weight on structural factors that limit opportunities for these households-potentially including bad geography (Jalan and Ravallion 2002), disease (Sachs and Malaney 2002), poor institutions (Acemoglu et al. 2001, 2005), or other factors that individual households cannot control. For this reason, they are also referred to as structural poverty traps (Barrett and Carter 2013). While evidence of multiple equilibria is most common in remote pastoral areas (Lybbert et al. 2004; Barrett et al. 2006), a large number of papers find evidence of single equilibrium poverty traps across a range of contexts (including Naschold 2012; Giesbert and Schindler 2012; Kwak and Smith 2013; McKay and Perge 2013; Naschold 2013, and Quisumbing and Baulch 2013). In these cases, it is even more challenging to design effective anti-poverty policies, since they must tackle deeper, structural causes of poverty. Many studies consider both single and multiple equilibrium traps and Barrett et al. (2016) conclude that "there is overwhelming evidence that poverty traps exist, of both the single and multiple equilibria varieties" (p. 321) but that there is more to learn about the specific mechanisms causing these poverty traps. ${ }^{3}$

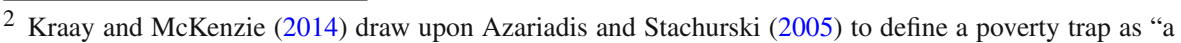
set of self-reinforcing mechanisms whereby countries start poor and remain poor: poverty begets poverty, so that current poverty is itself a direct cause of poverty in the future" (p. 127). In a footnote, they state that "others also refer to a single, poor, dynamic equilibrium as a structural poverty trap (for example, Barrett and Carter 2013; Naschold 2013), but we do not use this definition in our paper." Banerjee and Duflo (2011) also focus on multiple equilibria, noting that a poverty trap occurs "whenever the scope for growing income or wealth at a very fast rate is limited for those who have little to invest, but expands dramatically for those who can invest a bit more" (p. 11). In contrast, they state that "if the potential for fast growth is high among the poor, and then tapers off as one gets richer, there is no poverty trap" (p. 11).

3 Other empirical evidence of poverty traps is found in agricultural areas (Dercon 1998; Lybbert et al. 2004; Carter and Barrett 2006), human capital investment (Emerson and Souza 2003; Das 2007), and assets (Zimmerman and Carter 2003; Carter and May 1999, 2001; Adato et al. 2006). Similarly, the growing literature on the importance of institutions (Acemoglu et al. 2001, 2005) and the historical determinants of development (Nunn 2008, 2009) can be interpreted as causing low-income poverty traps. Barrett et al. (2019a) highlight recent research on a range of mechanisms and their implications for policy.
} 
We prefer to use poverty traps to refer to both multiple equilibria and single, low equilibrium situations, since in either case households can be stuck in poverty (whether in the low equilibrium or a low equilibrium) and because the term is popularly understood to mean someone who is stuck in poverty generation after generation (which can occur in both). Our model allows for multiple equilibria at the micro-, meso-, and macro-levels, thus integrating into the literature as broadly as possible. Even with the model remaining the same, the specific context determines whether agents in our model may exist in a structural poverty trap, a scenario with multiple equilibria, or no poverty traps at all, as discussed more below.

Second, because poverty traps are inherently difficult to identify empirically, Barrett et al. (2016) emphasize that "the absence of evidence is not evidence of absence," noting that current empirical studies may thus fail to identify poverty traps even when poverty traps might exist, due to these data limitations and fundamental estimation challenges (p. 314). By using an agent-based model to generate data in a context in which several poverty traps are present by design, we are able to evaluate the contexts in which poverty traps exist.

Third, poverty trap studies of a single level of analysis - whether individuals, households, or countries - may not observe the ways in which different factors interact to cause poverty. Geographic factors can strongly influence household welfare and create geographic poverty traps (Jalan and Ravallion 2002). For example, access to roads and markets can improve individual welfare (Stifel and Minten 2017) and incentivize greater technology adoption and local economic growth (Berg et al. 2018; Stifel et al. 2016). At the national level, institutions influence individual incentives, property rights, access to education and health, and opportunity (Acemoglu et al. 2005; Acemoglu and Robinson 2013), indicating that similar households in different institutional environments may have drastically different poverty dynamics. To include this level of complexity, we develop a model of fractal poverty traps, which Barrett and Swallow (2006) define as occurring when "multiple dynamic equilibria exist simultaneously at multiple (micro, meso, and/or macro) scales of analysis and are self-reinforcing through feedback effects" (p. 3). Theoretical models provide a range of explanations for persistent poverty among certain households or countries, but existing empirical studies may miss important heterogeneity across different contexts. ${ }^{4}$ We explore how much complexity can arise even with a relatively simple fractal poverty trap model. We find rich complexity even by only adding two levels to an individual poverty trap model, and adding more levels or additional types of traps at each level would increase this complexity considerably.

\section{A fractal poverty trap model}

This section introduces our three-level fractal poverty trap model. At the lowest level, individuals face a micro-level poverty trap through the choice of a low-return or a

\footnotetext{
4 An additional layer of complexity involves individual decision making across a range of choices, including education, health, jobs, and more. While many theoretical models focus on specific decisions, individuals live in diverse contexts and this complexity may influence the conditions under which individuals remain trapped in poverty. Empirical studies often address this challenge by developing asset indices. Our model focuses on analyzing fractal layers of poverty traps rather than a complex set of individual choices.
} 
high-return technology with a fixed cost. At the meso- (neighborhood or regional) level, we focus on access to markets by introducing the endogenous appearance of traders, who give up production in order to focus on transporting goods from other farmers to markets in mutually beneficial ways. At the macro- (country) level, we use the median voter theorem to endogenously determine a tax rate which is used to fund public goods. The public goods reduce the costs of technology adoption in a way that is accessible and beneficial to a broader cross section of citizens and, as a result, can drive increased technology adoption, use of markets, and higher income levels.

While we focus our analysis on agricultural production and markets, the interpretation of this model could easily be extended to other applications where households face their own constraints (such as lumpy investments in agriculture, human capital, or migration), regional markets may or may not arise (due to social networks, poor infrastructure, low levels of trust, or costly transportation), and countries suffer from macro-level poverty traps (possibly from bad geography, poor institutions, lack of property rights, or weak legal systems). While we provide a specific story to motivate our model at each level, our main contribution is a flexible, fractal poverty trap model, which we believe could be applied to a variety of contexts.

\subsection{Micro-level model}

We base our micro-level model on Ikegami et al. (2019). Consider a representative individual with a fixed level of total factor productivity (TFP, $\alpha$ ) and an initial capital level of $k_{0}$. Total factor productivity does not change with time but households invest in capital through time $(t)$. Total factor productivity is a technology multiplier that measures the potential to earn income on a individual's farm and, as such, it can represent household characteristics (such as ability) or farm characteristics (such as the quality of the land or the amount of rainfall).

Given their levels of TFP and capital, individuals choose how to maximize income in period $t$. Each individual earns income through agriculture $\left(y_{t}\left(\alpha, k_{t}\right)\right)$ and chooses between a low-return technology and a high-return technology with a fixed cost $(G)$, that creates a non-convexity such that:

$$
y_{t}\left(\alpha, k_{t}\right)=\max \left\{\begin{array}{l}
f_{L}\left(\alpha, k_{t}\right)=\alpha k_{t}^{\gamma_{\mathrm{L}}} \\
f_{H}\left(\alpha, k_{t}\right)=\alpha k_{t}^{\gamma_{\mathrm{H}}}-G
\end{array}\right.
$$

where $0<\gamma_{\mathrm{L}}<\gamma_{\mathrm{H}}<1$. In agriculture, for example, a high-return technology can include modern farming methods (which can require learning), high yielding seed varieties (which require fixed expenditures on seeds, fertilizer, and other inputs), or cash crops such as fruit trees or coffee plants (which require a large initial expenditure and may take several years to profit). While we focus on agriculture, this framework can easily be applied to human capital investments, migration, or other individual choices and income strategies. Poverty traps resulting from lumpy investments also require credit market failures and we do not allow for borrowing (Barrett and Carter 2013). Recent empirical evidence further suggests that access to credit allows certain individuals to transition to high-return technologies with fixed costs that are otherwise inaccessible to them (Banerjee et al. 2019). 


\subsection{Meso-level model}

The meso-level is less commonly analyzed in the poverty trap literature, and we model it through the growth of traders that provide improved market access to farmers. Certain entrepreneurs choose to become traders by giving up agricultural production in order to earn money by charging fees to transport goods. As more efficient transportation options, traders can charge individual farmers fees in mutually beneficial agreements and, as a result, we interpret their presence as a neighborhood breaking a meso-trap.

Initially, all individual agricultural producers described in the micro-level model transport their own goods to market, possibly on foot or using draft animals. However, this transportation is costly and farmers lose some of their crop while en route. Assume that only a portion $\left(\theta_{L}\right)$ of a farmer's harvest reaches market if they transport it themselves. Becoming a trader requires sufficient wealth to purchase a pushcart (or bike, car, wagon, etc.) with which they can efficiently transport large amounts of goods to market. We model this through a fixed capital threshold $\left(k_{T}\right)$ that a farmer must surpass before being able to cash in their capital for a pushcart. The pushcart can transport the crops of at least 15 people (the 15 neighbors in the grid space) and does so while maintaining a greater proportion of each farmer's harvest $\left(\theta_{H}>\theta_{L}\right)$.

In each neighborhood without an incumbent trader, the farmer with the highest level of capital compares his potential income as a farmer with his potential income as a profit-maximizing trader. In order to predict one's potential income as a trader, the individual evaluates each neighbor to determine the maximum fee that they would be willing to pay to a trader. After gathering this information from each of the fifteen other farmers in the neighborhood, the potential trader calculates the fee that would maximize their total revenue if they were to become a trader. If this is greater than what they would earn as a farmer (and they have sufficient capital), then they decide to become a trader, and we only allow one trader per neighborhood. We assume that a trader knows the potential fee that each of their 15 neighbors would be willing to pay but is only able to charge a single price for all potential clients, thus acting as a local monopolist charging the transportation fee $(F)$ that maximizes total revenue. After the trader chooses their total revenue maximizing fee, the neighbors then decide whether to continue with independent farming or to accept the trader's offer to transport their goods (which we call commercial farming). Traders and farmers use adaptive expectations for predicting future profits, fees, and capital levels in their neighborhood (to check if they could become a trader). In the second period they assume that those will remain the same as the first period, but for all subsequent periods they assume that the growth rate of those values will remain the same as their growth rates in previous periods. If an individual farmer lives in a neighborhood that already has a trader, they forego this calculation because we assume a monopoly.

\subsection{Macro-level model}

Our macro-level model is motivated by the recent institutions literature, which shows that historical events cause countries to develop persistent political and economic institutions, which then drive economic growth in some countries but not others (Ace- 
moglu et al. 2005; Acemoglu and Robinson 2013). Acemoglu and Robinson (2013) state that growth-promoting, "inclusive economic institutions require secure property rights and economic opportunities not just for the elite but for a broad cross section of society" (p. 75). We assume inclusive political institutions where each country is a stable democracy in which each individual agent votes (non-strategically) for their preferred tax rate and the chosen tax rate is determined by the median voter theorem. ${ }^{5}$ Within this political system, we allow for endogenously determined economic policies and find that, even in well-functioning democracies, macro-traps can arise that limit individual opportunity. ${ }^{6}$

In our model, the median voter chooses their preferred tax rate, which is then used to fund the provision of a non-rivalrous and non-excludable public good in each time period. Each forward-looking individual agent votes for the tax rate that maximizes their own individual expected utility. A high tax rate would lead to greater government revenue and therefore more public goods in the next period, while a low tax rate would mean greater after-tax income available for private investments and current consumption. An individual's choice would therefore depend not only on their own income and wealth levels (which would determine how valuable the public good would be for them relative to the reduction in their current income due to taxes) but also on the overall income level of their economy (if overall incomes are high, even a low tax rate would suffice to generate high government revenue). Consequently, the median tax rate and therefore the level of public goods provided will differ based on the underlying distribution of wealth, which is itself ultimately based on factors including initial conditions and geography in a country. As explained below, this macro-economic policy ranges from less inclusive-in which case low taxes provide little public goods provision that limit opportunities for the poor-to more inclusivein which case higher taxes provide greater levels of public goods, which make high return technologies broadly accessible. These investments in public goods, in turn, influence whether households are able to escape micro-level poverty traps and whether markets develop at the meso-level.

\subsubsection{Voting and tax revenue}

We assume that individuals possess complete information about their own income levels, the aggregate income (or GDP) in their economy (which will determine the total tax revenue raised by any marginal tax), and the level of public goods provision resulting from any given level of tax revenue. With this information, each individual citizen votes for their preferred marginal tax rate $\left(\tau_{i}\right)$ and the median voter's preferred tax rate $\left(\tau^{*}\right)$ wins and is implemented that period. Based on the chosen marginal tax

\footnotetext{
5 Morrow and Carter [2017] show how important income dynamics and voter's information about income dynamics are to democratic elections, showing that limited upward mobility can rapidly increase support for redistribution in certain cases.

6 While we could explain macro-economic poverty traps through other factors, such as coordination failures, corruption, or the potential transition from a dictatorship to a democracy, this focus on taxation and public goods provision provides a relatively clear link with the remainder of our model. Explaining the transition to democracy and growth of s remains vitally important (Acemoglu and Robinson 2005), we leave aside this complexity for simplicity.
} 
rate $\left(\tau^{*}\right)$, the government collects a share $\tau^{*}$ of each individual's income and collects total revenue $R=\sum_{i} \tau^{*} y_{i}$.

\subsubsection{Public goods}

The government uses this revenue to pay for a per-period public good, which we model as a reduction in the fixed cost of adopting the high-return technology (a reduction in $G$ ). By design, this investment is a public good (it is assumed to be non-rivalrous and non-excludable) that can be broadly beneficial while helping a range of households escape poverty, which could indirectly enable the growth of local markets. This investment can be interpreted in a few specific ways. First, a government may provide more education, which helps individuals learn more easily and adopt technologies more rapidly (Foster and Rosenzweig 2010) and can increase agricultural yields and incomes (Huffman 2001). Second, extension services can produce a range of economic benefits, including speeding technology adoption by providing farmers with more information (Evenson 2001). Third, general research and development can facilitate the adoption of new technologies by making them more suitable for a given region or providing localized information (Anderson and Feder 2004). Fourth, governments may subsidize technology adoption so as to improve growth while making technologies more affordable. Fifth, weather forecasting and plant epidemiological research is essential to farming and can be interpreted as public goods that a government provides annually, if not more frequently (Craft 1999; Rosenzweig and Udry 2019).

We assume that the per-period public goods provision depends on the total tax revenues collected according to $G=\frac{0.45}{1+a R^{2}}$. At one extreme, the government collects little tax revenue and provides limited public goods investment, which may result in high-return agriculture remaining unaffordable for the poor. We interpret this system as not inclusive, since it fails to help poorer citizens climb out of poverty, while wealthier citizens will be able to afford and benefit from high-return agriculture. At the other extreme, the government collects higher tax revenues and funds public goods so as to facilitate technology adoption. In line with Acemoglu and Robinson's (2013) definition of inclusive economic institutions, this scenario benefits a broad cross section of society and can unlock greater individual agricultural productivity. Our interpretation also parallels the model in Arora and Chong (2018), where improved institutional quality corresponds with higher taxation and improved public goods provision. We interpret higher public goods quality as breaking free from a macro-trap (potentially caused by low-quality institutions) even though not every individual gains. Given our parameters and as seen in Fig. 1, the fixed cost of high-return technology starts at 0.45 and declines as total tax revenue increases.

This specific functional form provides a non-convexity in public goods provision and is based on assumptions that, at some level of public goods provision, there are economies of scale. These might arise because governments gain buying or monopsony power that lowers costs, provide services to bigger populations, or because some beneficiaries are easier to reach than others. Economies of scale in public goods provision are commonly assumed in a range of political economy studies on state size 


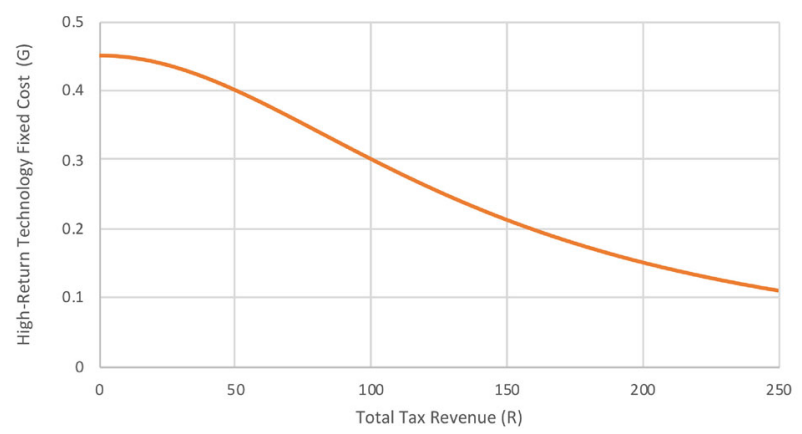

Fig. 1 High-return technology fixed cost and tax revenue

and public goods provision (Alesina and Spolaore 1997; Alesina et al. 2004; Stiglitz 2015). As a result, we assume a range over which public goods provision has increasing marginal impacts. Eventually, it becomes very costly to provide public goods because the remaining areas or individuals are the most difficult to reach or because of congestion or coordination problems (Alesina and Spolaore 1997). This increases the costs and decreases the marginal impact after a certain point. The macro-poverty trap is similar to the micro- and meso-traps, since the non-convexity generated by this additional feature can also trap societies in poor outcomes. Even though the median voter's preferred policy is chosen, the median voter in certain regions will choose low taxes and low levels of public infrastructure, which can trap groups in poverty.

\subsubsection{Macro-trap}

To understand the macro-poverty trap, it may be helpful to consider how the aggregate level of income as well as its distribution affects the median tax rate and therefore the total revenue and the level of public goods provided.

First, aggregate national income is important. If aggregate incomes are low, then an unfeasibly high tax rate may be required to generate adequate revenue to help individuals adopt the high return technology. On the other hand, if aggregate incomes are high, a low tax rate may be sufficient in order to generate the revenue required for adequate provision of public goods. This results in a macro-poverty trap similar to the micro- and meso-traps since the non-convexity generated by this additional feature can also trap societies in poor outcomes. Even though the median voter's preferred policy is chosen, the tax revenue could result in low levels of public infrastructure, which can trap groups in poverty.

Second, the distribution of income and wealth within a country can also affect the level of public goods provided. Very poor individuals who cannot adopt the high-return technology even with a high level of public goods vote for a $0 \%$ tax rate. Very rich individuals who can easily afford the high-return technology without any provision of public goods and traders who do not need the public goods themselves also vote for a $0 \%$ tax rate. Individuals between these two extremes vote for higher taxes because the provision of some level of public goods helps ease their transition to the high-return technology. Among them, poor individuals who are on the cusp of being able to afford 
the high-return technology vote for very high tax rates since they need a high-level of public goods in order to transition to the high-return technology. Consequently, a country where the distribution of incomes is very unequal where some individuals are very rich and several others very poor would lead to a situation with a low provision of public goods which in turn prevents the middle class from transitioning to the highreturn technology. On the other hand, in a more equal society where most individuals are middle class, the median tax rate would be high enough to facilitate the provision of public goods that are adequate to allow those individuals to transition to the high-return technology. ${ }^{7}$

Since the macro-trap is based on both aggregate income as well as its distribution, it is inextricably linked to initial conditions and the resulting individual-level income and wealth outcomes driven by micro- and meso-processes. In turn, the macro-economic situation also affects the micro-process of technology adoption by individual farmers since the macro-economically determined level of public goods provision affects the cost that individual farmers have to pay in order to transition to the high return technology.

\subsection{Intertemporal utility maximization}

Among farmers, individuals choose to either use the low- or high-return technology and to engage in independent (not using the trader) or commercial (using the trader) farming. Together, in each period households choose to maximize income among the four agricultural choices, where the commercial options are only available if there is a trader in one's neighborhood:

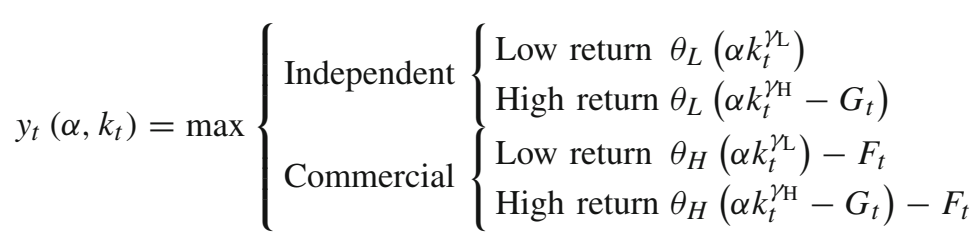

Each individual can also choose to be a trader, in which case they earn: $y_{t}=$ $f_{\text {Trader }}=\left(F_{t}\right)\left(\#\right.$ of Client $\left._{t}\right)$.

After maximizing income, $\tau^{*} y_{t}\left(\alpha, k_{t}\right)$ is paid in taxes and the household determines optimal levels of consumption $\left(c_{t}\right)$ and investment in capital $\left(i_{t}\right)$ so as to satisfy the household budget constraint:

$$
c_{t}+i_{t}=\left(1-\tau^{*}\right) y_{t}\left(\alpha, k_{t}\right)
$$

Capital grows according to:

$$
k_{t+1}=i_{t}+(1-\delta) k_{t}
$$

\footnotetext{
7 Appendix $\mathrm{C}$ includes more detailed explanations of these relationships using results obtained from the simulations of the model. 
where $\delta$ is the rate of depreciation. Farmers will accumulate capital until they reach their respective steady state (which depends on their individual TFP and initial capital levels), while traders will maintain capital levels just above the threshold to become a trader $\left(k_{T}=4\right)$.

Each individual maximizes:

$$
\max \left[\phi \ln \left(c_{t}\right)+(1-\phi) E\left(\ln \left(y_{t+1}\right) \mid F_{t}, F_{t-1}, y_{\operatorname{Trader}, t}, y_{\operatorname{Trader}, t-1}\right)\right]
$$

subject to:

$$
\begin{aligned}
c_{t}+i_{t} & =\left(1-\tau^{*}\right) y_{t}\left(\alpha, k_{t}\right) \\
k_{t+1} & =i_{t}+(1-\delta) k_{t} \\
R^{*}\left(\tau^{*}\right) & =\sum_{i} \tau^{*} y_{i} \\
G\left(\tau^{*}\right) & =\frac{0.45}{1+a R^{* 2}}
\end{aligned}
$$

Our agents value current consumption and future income, whether by a given individual or the next generation. We choose to have our agents face this overlapping generations problem for several reasons. First, this model can be applied to situations where individuals either make decisions valuing their own current and future welfare or their own current welfare and that of future generations. Either interpretation is captured through $\phi$, which measures how much an agent values current consumption relative to the expected income of their future self (or, alternatively, how much a given agent values the consumption of the current generation relative to the income of the next generation). As such, this model parallels models of family altruism across overlapping generations (as done by, for example, Lambrecht et al. 2006; Michel et al. 2006). ${ }^{8}$ Second, this formulation is more reasonable with adaptive expectations. Given the high degree of uncertainty that exists in our fractal model due to mesoand macro-level changes relying on complex dynamics, it is difficult for individuals to hold rational expectations about the future and they may not wish to extrapolate beyond one period. In order to calculate future consumption, agents would need to have expectations about what would happen two periods ahead and if they care about future utility recursively (as is standard and equivalent to the infinite horizon problem), they would need to have expectations infinitely far into the future. In highly uncertain environments, adaptive expectations may be a more reasonable assumption than rational expectations (see, for example Heiner 1989 and discussions in Rosser 1997, 1999). While we prefer this specification, we calibrate $\phi$ so that our OLG steady state approximates those in the infinite horizon model (as shown in Online Appendix A).

We use this fractal poverty trap model to generate data which we analyze in the following sections. We run simulations for 300 countries through 100 periods, with each country consisting of 576 individuals across a $24 \times 24$ grid, each with a randomly drawn TFP $(\alpha)$ and initial capital level $\left(k_{0}\right)$. Each country is divided into 36

\footnotetext{
8 Lambrecht et al. (2006) use the log of current consumption while noting that the functional form for future income only needs to be continuous, differentiable, and concave.
} 
neighborhoods (a $6 \times 6$ grid of neighborhoods), each of which includes a $4 \times 4$ grid of households. Otherwise, the analysis relies on numerical simulation of this model based on the parameters presented in appendix. We calculate a range of individual, neighborhood, and country characteristics and analyze their evolution through time. By design, our model encapsulates many potential outcomes, given the endogenous decisions of certain individuals to become traders and an endogenously evolving tax rate.

\subsection{Stages of decision making}

Our agents make decisions in five stages:

1. To farm or not to farm. Based on all available information at the start of the round, the agent with the highest level of capital in a neighborhood without a trader chooses whether to be a farmer or a trader. Specifically, the agent looks at each of their fifteen neighbors and determines what fee each one would be willing to pay a trader, and then compares their expected profit from farming with their potential profit as a trader. If they decide to be a trader, they post their fees at the end of this stage. If a neighborhood already has a trader, the trader decides whether to continue trading (and determines the optimal fee as above) or switch to being a farmer.

2. How to farm. Once a trader (if one exists in the neighborhood) posts fees, individual farmers, decide their type of farming that period. This involves choosing whether or not to use a trader simultaneously with whether or not to use the high-return technology.

3. How much to pay in taxes. After agents choose optimal production based on Steps 1 and 2 above, they are informed about the economy-wide GDP and are asked to vote for their preferred tax rate in the period. First, the tax rate determines disposable income today according to the above budget constraint. Second, today's tax rate funds the next period's public goods $\left(G_{t+1}\left(\tau^{*}\right)\right)$ and therefore affect future output.

4. Consume and save. Following the realization of today's tax rate, agents consume and save based on the maximization problem outlined above, which weights a combination of current consumption and future income. At the end of this round, capital depreciates.

Following the end of all four stages, the process repeats itself.

\subsection{Escaping poverty traps}

Poverty traps exist when individuals remain poor indefinitely into the future and we first need to define what it means to be poor before exploring whether or not someone is trapped in poverty in our model. In many cases, an income-based poverty line is defined as the income level required for a minimum standard of living. While incomebased poverty lines have many advantages, they create artificial breaks that classify essentially identical individuals near the threshold as either poor or non-poor. In a world of smooth income distributions, these negatives can prove problematic. In contrast, others define poverty lines based on behaviors, assets, or other traits (see, for example, 
Carter and Barrett 2006). As explained below, we define poverty based on individual behavior rather than income. Furthermore, poverty is commonly discussed in static terms, with a household either being poor or non-poor based on a current measure of income, consumption, or assets. However, it is important to distinguish a static poverty line, separating currently poor and non-poor households, from a dynamic poverty line, separating households that remain structurally poor and those that eventually escape poverty. As a dynamic poverty line, Barrett and Carter (2013) define the Micawber frontier as dividing "those agents ... who (in probability) converge to a high-income equilibrium, and those ... who in expectation collapse to a low-level, poverty trap equilibrium" (p. 980). ${ }^{9}$ We use a similar concept as well.

In this paper, we focus our analysis primarily on whether or not individuals dynamically break out of the micro-based poverty trap, meaning that they transition from the low- to the high-return technology (and possibly to a trader) by the end of our simulation. We highlight use of the low-return technology as a poverty trap because it focuses on behavioral decisions, rather than arbitrary divisions in income levels that depend more on the parameterization of our model. We make two adjustments to the Micawber frontier analyzed in micro-level models by Barrett and Carter (2013) and Ikegami et al. (2019). First, both papers base their Micawber frontier on the technology that an individual uses in their steady state. Because our tax revenues and trader fees continue to display a little bit of dynamics (even after 100 rounds), we do not necessarily reach a stable steady state in many cases. As a result, we refer to the prevailing Micawber frontier and provide videos and images based on what the prevailing Micawber frontier would be in any given round. Second, we classify two lines that help emphasize the importance of meso- and macro-determinants of individual technology choices. The prevailing lower Micawber frontier is the individual TFP below which every individual engages in low-return farming (and above which at least some individuals do not). ${ }^{10}$ The prevailing upper Micawber frontier is the individual TFP above which no individual engages in low-return farming (either engaging in high-return farming or being a trader). These two lines provide us with three potential groups. First, those below the prevailing lower Micawber frontier are stuck in poverty, regardless of one's broader context, since their individual TFP levels are too low. This can be thought of us a structural poverty trap. Second, those between the two lines are in a geographic poverty trap, a concept introduced by Jalan and Ravallion (2002), since identical individuals might end up in or out of poverty based on meso- or macro-context. For example, breaking free from the poverty trap might be due to a combination of individual factors (such as a high individual productivity level), neighborhood factors (the existence of a trader, possibly with agreeable fees), and country factors (such as a tax rate that drives down the fixed cost of the high-return technology). Third, those above the prevailing upper Micawber frontier are non-poor regardless of context.

\footnotetext{
9 The Micawber frontier or threshold is based on Zimmerman and Carter (2003), who based the name on Lipton (1994).

10 Our micro-model is based on Ikegami et al. (2019), who find a downward sloping Micawber frontier than then turns vertical, resulting from their higher range of initial capital levels. As depicted below, we use a lower set of starting initial capital levels and, as a result, our two prevailing Micawber lines correspond to their vertical section.
} 
The transition out of poverty can take one of several paths. In our model, all individuals start poor in low-return independent farming. In this context, low initial capital levels cause farmers to rely on the low-return technology and they produce independently because they lack access to markets (represented through traders). ${ }^{11}$ While everyone starts in low-return independent farming, some individuals escape to alternative livelihoods through a range of pathways. First, certain individuals with sufficiently high productivity levels will transition to high-return independent agriculture. ${ }^{12} \mathrm{Sec}-$ ond, wealthy high-return independent farmers may attain sufficient capital to become a trader, with their decision further depending on the potential willingness-to-pay of consumers in their neighborhood. Third, once a trader appears in one's neighborhood, individual farmers might transition into low-return commercial farming, although this is rarely a final outcome. Given that these individuals still engage in low-return agriculture and their final income levels overlap considerably with low-return independent farming as shown below, we consider these individuals to still be in the poverty trap. After a few periods of low-return commercial farming, many individuals transition to high-return commercial farming, where they earn noticeably higher incomes, benefitting from both the high-return technology and the improved market access provided by traders.

We primarily focus on individual livelihoods as determining whether or not an individual is poor. For a given individual, making the transition out of the low-return technology means earning higher incomes. However, given our range of parameters, the entire distribution of our simulation results in considerable overlap across these distinct income sources. For example, the range of individual TFP levels means that we observe a wide range of income levels, even within a given income source. Figure 2 presents the density function of incomes by income source after 100 periods of our baseline model. Even by the end of our model, $64 \%$ of individuals remain trapped in poverty, with $63 \%$ engaging in low-return independent farming (with their range of incomes stretching from 0.3 to 1.1 ) and $0.5 \%$ choosing low-return commercial agriculture (with a range from 0.3 to 1.6 ). Otherwise, $15.7 \%$ use high-return independent farming and $18.6 \%$ reach high-return commercial farming, with a noticeably higher income distribution. Traders $(2 \%)$ are not depicted because their income levels average 6.7 and reach far higher, making the figure harder to read for the farmers. This illustrates how there is more to income than one's income source and we focus mainly on income source but also compare incomes in the remainder of our analysis.

Furthermore, individual incomes will change due to a particular neighborhood's trader access and fees and a country's chosen taxation rate and public goods provision. Because our model integrates considerable variation across individuals who operate within heterogeneous neighborhoods and countries, we obtain a complex range of

\footnotetext{
11 They can be thought of as subsistence farmers-although this term often conflates multiple traits and often lacks a specific, uniform meaning (Miracle 1968)_and we classify them as low-return independent farmers to frame them explicitly within our model.

12 Without access to a trader, this scenario parallels the model of Ikegami et al. (2019), in which sufficiently productive individuals inevitably transition to the high-return technology, very low productivity individuals remain trapped using the low-return technology (a single equilibrium poverty trap), and an intermediate ability range uses the high-return technology if they begin with sufficiently high capital levels (a multiple equilibrium poverty trap).
} 


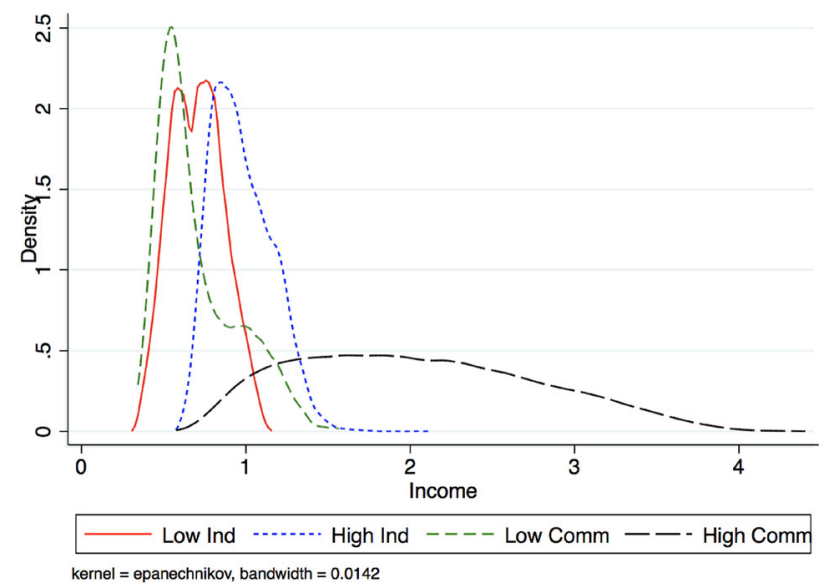

Fig. 2 PDF of income distribution by income source
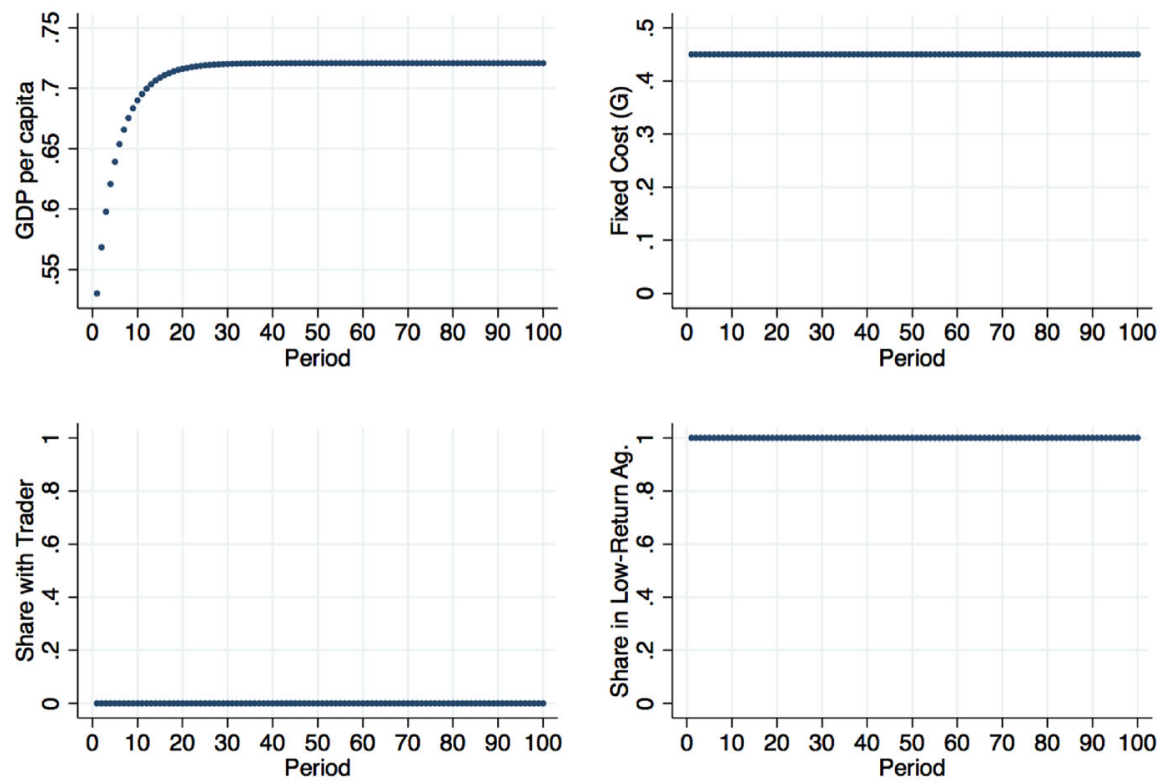

Fig. 3 Country \#8 case study

outcomes and incomes that remains difficult to classify but, in many ways, makes it more applicable to the real world. Otherwise, we remain intentionally agnostic about specific poverty lines and focus our analysis on two concepts: (a) for individuals in specific contexts, transitioning out of low-return farming improves one's welfare and (b) in a complicated and continuous range of incomes, higher incomes are better and specific poverty lines might differ by context. 


\subsection{Case studies: country examples}

To further illustrate the potential outcomes arising within our model, we begin by presenting case studies. Figure 3 highlights country \#8, where income levels are initially low and the low TFP endowment across individuals causes the entire country to remain trapped in poverty. The upper left diagram shows that the GDP per capita converges to around 0.72 , while the remaining graphs show that the public good is never funded (zero taxation), nobody becomes a trader, and all individuals use the low-return technology. Thus, the country, every neighborhood, and each individual remains stuck in a single equilibrium poverty trap at each level of analysis.

In contrast, Fig. 4 highlights country \#9, which experiences rapid initial growth, a brief stable period, and then a rapid escape to a higher level of GDP per capita. This transition occurs because the country escapes the macro-trap as taxes drive down the fixed cost of technology adoption (top right) and because neighborhoods begin to escape their meso-traps through the rise of traders (bottom left). These changes allow almost $80 \%$ of individuals to escape the poverty trap (bottom right). In this case, country-level factors drive the provision of public goods (through higher tax rates) before period 10 and over $60 \%$ of individuals immediately transition out of low-return agriculture. Then, traders arise shortly after, with a trader in every neighborhood by period 30, and additional farmers gradually escape through the end of our simulation. Together, the provision of public goods and rise of traders sparks rapid growth in GDP per capita starting around period 17 . Within country \#9, the country as a whole breaks out of the macro-trap, every neighborhood escapes the no-trader trap, and individuals
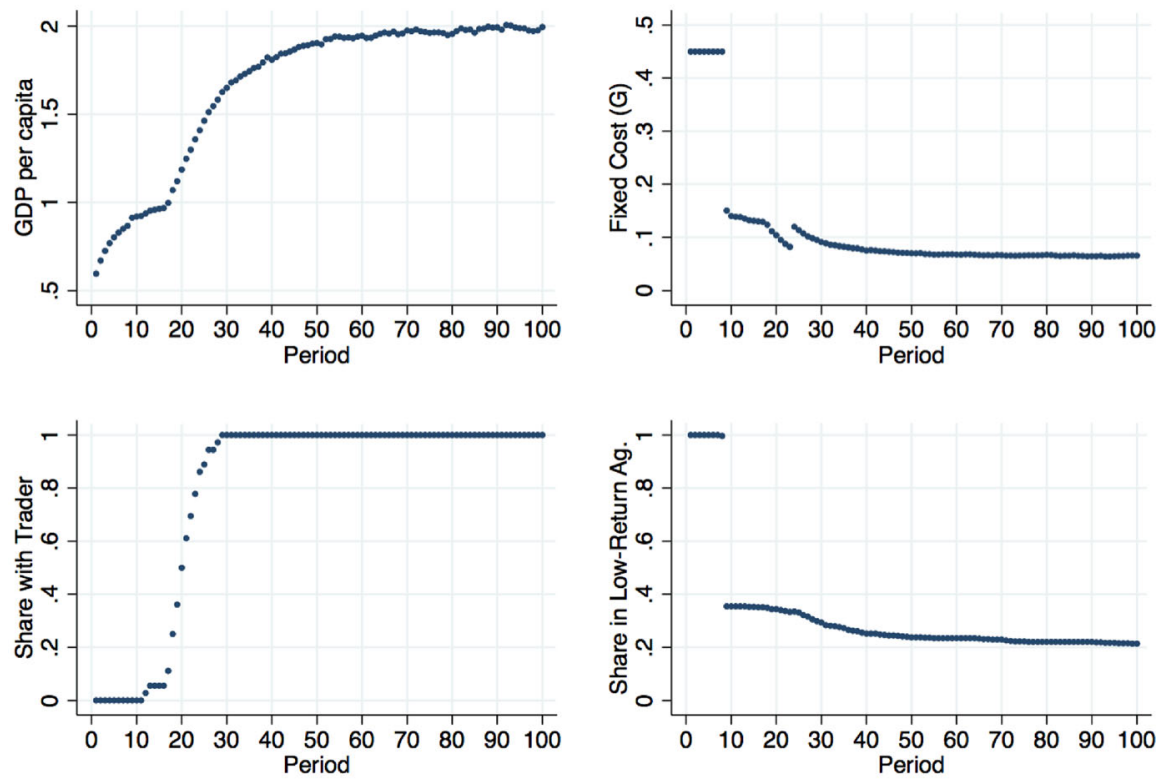

Fig. 4 Country \#9 case study 
face a multiple equilibrium trap with some escaping from the low-return technology, while others cannot.

Thus, while the model remains the same in both countries, we see a range of outcomes based on the set of individual productivity and initial capital levels. In some cases (country \#8), entire countries remain trapped in poverty, with no traders and everyone using the low-return technology. Elsewhere (country \#9), traders arise and tax rates increase to provide broadly beneficial public goods, both of which unlock rapid growth allowing most individuals to escape poverty. In this comparison, individual TFP values range from 0.80 to 1.04 in country \#8 but 0.75 to 1.43 in country \#9, with the higher end of the distribution helping drive the rise of traders and escape of most individuals, while those at the lower end are unable to escape poverty, even with access to traders and public goods.

\section{Empirical analysis}

\subsection{Evidence of poverty traps}

Before conducting our main analysis, we first present preliminary evidence on growth and changes in the income distribution through time. Across a range of methods, we find consistent evidence of divergence across multiple equilibria.

Quah (1996, 1997) use cross-sectional data to analyze distributions of national income levels, finding evidence of "twin peaks" that indicate divergence across countries. We present similar distributions in Fig. 5 to present visual evidence regarding if and when convergence and/or divergence occurs. First, we compare the distribution of average incomes through time by plotting the probability density function in years 1, 21, 41, 61, 81, and 100-for the macro- (Fig. 5a), meso- (Fig. 5b), and micro-level (Fig. 5c) data. In the macro- and meso-graphs, we find similar evidence of divergence across both countries and neighborhoods. In each, there is initially a unimodal distribution in which all countries or neighborhoods begin with low average income levels centered around 0.5 . Through time, divergence occurs as a large peak develops around 0.75 , while some countries and neighborhoods transition to higher income steady states ranging from around 1.5-2.5. It appears that most countries reach their steady state, since we see relative stability in the distribution between years 81 and 100 , although the share of countries in the low-income steady state continues to fall slowly. The micro-evidence is similar, with the vast majority of individuals trapped at low incomes while some escape poverty through farming (earning incomes around 2-4) and a few becoming wealthy traders (incomes up to around 12).

Many poverty trap models predict that those stuck in poverty will experience zero growth (due to an absolute poverty trap) or slower growth (due to a relative poverty trap). In the case of multiple equilibria, we expect to see no growth among those at a low-income steady state, rapid growth among those transitioning to the high-income steady state, and no growth again once the high-income steady state is reached. As done in Easterly (2006) and Kraay and McKenzie (2014), in Table 1 we present evidence on growth rates by initial income levels, which provides a convenient way to determine whether or not poor individuals, neighborhoods, or countries grow faster or slower in 

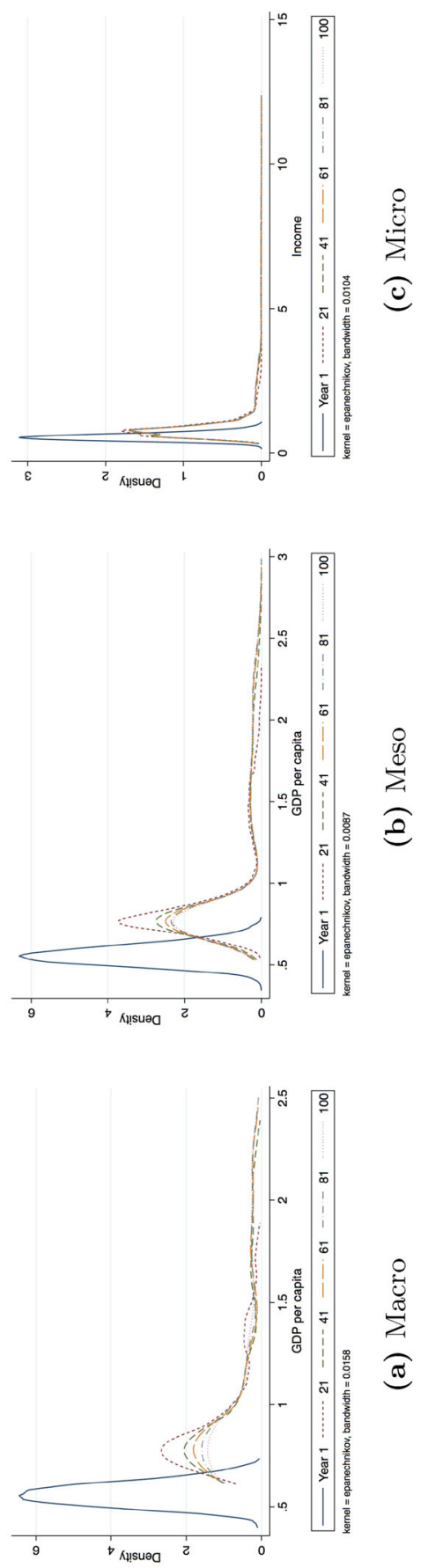

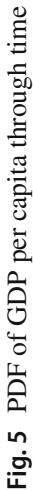


our model and whether or not a certain range experiences rapid growth. Using these methods, both Easterly (2006) and Kraay and McKenzie (2014) find little evidence of poverty traps, with positive growth among poor countries that is not considerably different from wealthier countries. Additionally, we present our results across different time periods to determine whether this growth is sustained and when it slows down. The average growth rates over all years increase by quintile. The initially poorest countries grow at $0.4 \%$ per year, while the initially wealthiest grow at $1.0 \%$ per year, resulting in divergence. Tracking growth rates through time, the poorest two quintiles experience early growth $(3.6 \%$ and $3.8 \%)$ as they converge on their steady state, but growth rates slow to $0-0.1 \%$ by year 30 . The initially wealthier countries experience both more rapid initial growth $(4.8 \%)$ and more sustained growth that does not approach $0-0.1 \%$ until year 60. Thus, while all groups appear to reach their steady state, the initially wealthier countries grow more rapidly and longer as they transition toward their higher income levels.

In Fig. 6, we plot average growth rates by initial income percentile as a way to provide a more detailed and visual depiction of these trends, as done in Piketty et al. (2017). Consistently across each level of analysis, the poorest two quintiles experience very low growth around $0.5 \%$ on average. Starting in the third quintile in both the macro- and meso-results, growth rates slowly increase and break $1 \%$ around the 90th percentile. In the micro-results, we see even stronger evidence of divergence and growing inequality. Those individuals with the lowest initial incomes grow enough to converge on the low-income steady state, while the majority of the distribution experiences low average annual growth rates of $0.4 \%$. Average growth rates increase among the initially wealthiest, reaching $1.5 \%$ at the highest percentile.

Thus, we see evidence of divergence at each level of analysis, with the initially wealthier individuals, neighborhoods, and countries growing fastest while transitioning to higher steady states.

\subsection{Graphical analysis through time}

Next, we graphically analyze transformations through time across a range of scenarios, highlighting the importance of individual as well as neighborhood and country characteristics. The following figures (and corresponding videos available online) depict individual job types: low-return independent farming (red), low-return commercial farming (green), high-return independent farming (blue), high-return commercial farming (black), and traders (yellow). Using the same random draw of individuals across all 300 countries used above, we run our simulation under four different scenarios: contexts where it is possible to escape both the meso- and macro-traps (upper right, the baseline case analyzed thus far), contexts where the macro-trap is forced by not allowing any taxation which results in no public goods provision (upper left), contexts where the meso-trap is forced by not allowing any individuals to become traders (bottom right), and contexts where the meso- and macro-traps are both forced (bottom left). Thus, each point depicts one of 172,800 individuals (576 in each of 300 different countries) and the same 172,800 individuals are depicted in each of the four scenarios. The four scenarios allow us to visualize the effects of the macro- trap (by 


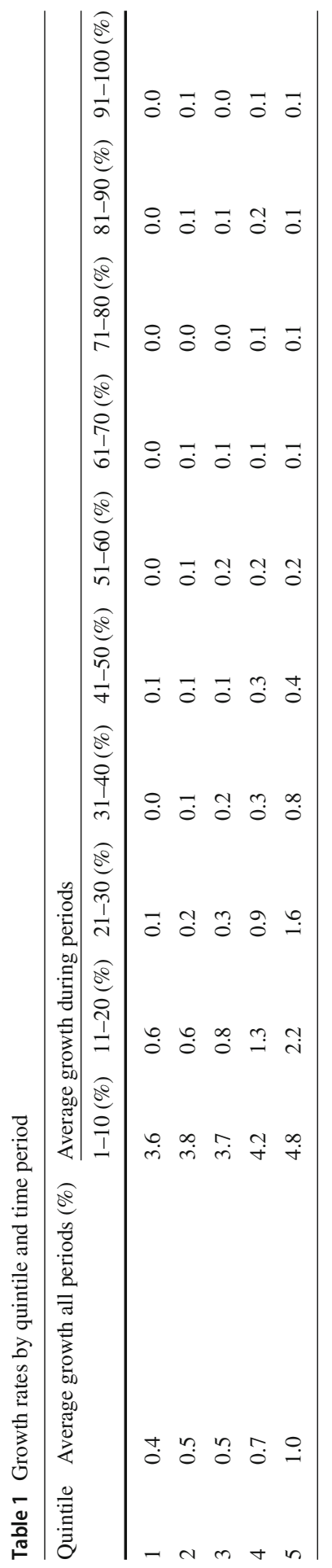



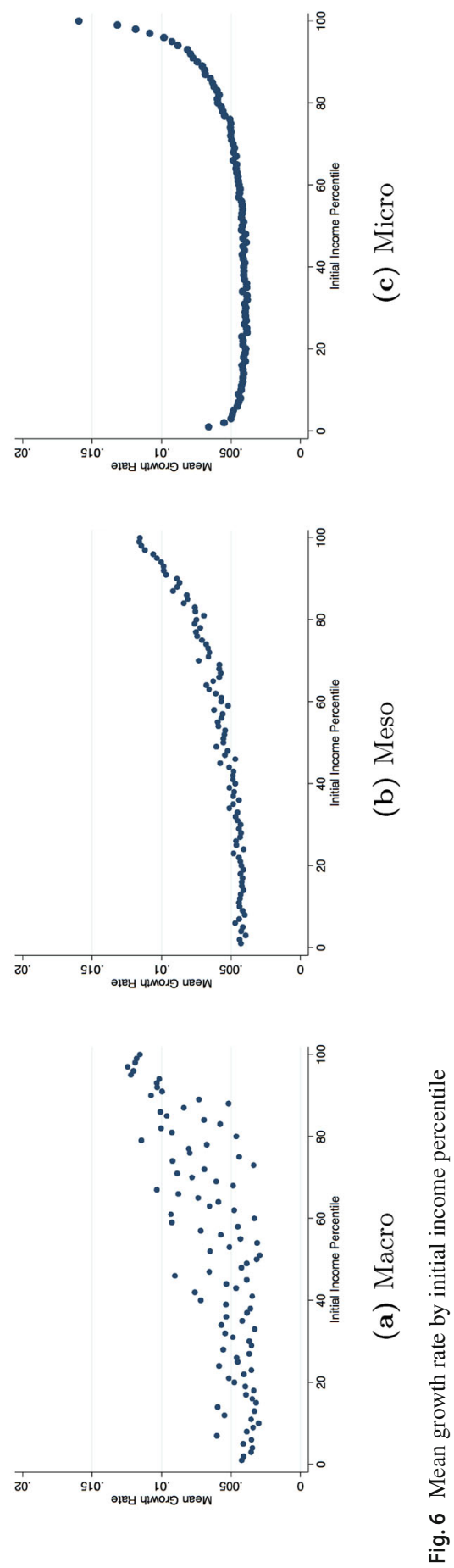
comparing along a given row) or the meso-trap (by comparing along a given column). The vast majority of individuals are low-return independent farmers but these markers are smaller than the other types (a quarter of the size) to make the dynamic changes more visible.

To illustrate the transformations that occur throughout our model, we present graphs depicting the evolution of individual occupations (with the two Micawber frontiers), current capital, incomes, and tax preferences. The graphs are available as videos on our online appendix and a few single-period snapshots are provided below. We organize our results in this section according to several concepts.

\subsubsection{Micawber frontiers and poverty traps}

Figure 7 depicts individual job types along with the prevailing lower and upper Micawber frontiers, separating individuals definitely stuck in poverty (left zone), individuals whose outcome depends on context (middle zone), and non-poor individuals (right zone). Micawber frontiers are dynamic concepts evaluating what someone does in their steady state and, while we do not always reach a clear steady state in our model, the final round provides a good proxy for the steady state in our model. It is useful to begin with both traps enforced (lower left), which is analogous to similar microlevel models (Ikegami et al. 2019). Here, there is a clear, single Micawber frontier that separates low and high-return independent farmers based on their individual TFP. Without the opportunity to break through the meso- and macro-traps, neighborhood and country characteristics do not matter and, given our low range of starting values, neither does initial capital (except for a few early periods where the prevailing Micawber frontier slopes downward). As seen in Figs. 8 and 9, there is a clear jump in both capital and income at the single Micawber frontier, but the steady-state levels are also increasing in TFP.

When countries can provide public goods but traders cannot arise within neighborhoods (lower right), we see several important changes. First, a geographic poverty trap appears between the two Micawber frontiers where, as explored more below, similar individuals may end up poor or non-poor based on the interactions between their own initial conditions and their meso- and macro-context. ${ }^{13}$ The prevailing lower Micawber frontier falls, since the provision of public goods facilitates technology adoption and helps farmers with intermediate TFP levels transition out of poverty. Also, the prevailing upper Micawber frontier shifts right because the negative impact of taxes dominates the benefit of cheaper technology adoption for this range of TFP values.

When traders can arise within neighborhoods but countries cannot provide public goods (upper left), the prevailing lower Micawber frontier also falls in relation to both traps being enforced, opening up a geographic poverty trap. ${ }^{14}$ This occurs as traders

\footnotetext{
13 Context does influence individual incomes outside of our geographic poverty trap zone, as seen in the current capital and current income graphs, for example, in the distribution of incomes below the prevailing lower Micawber frontier. However, our geographic poverty trap is defined based on individual behavior (or technology choice) rather than specific income levels.

14 It is also illuminating to observe the growth of traders, who need to maintain a level of capital above the minimum threshold (4 units of capital) but earn higher incomes from their fees. We chose the capital threshold to be feasible for high-TFP individuals, who will reach it automatically based on the high-return independent farming steady state, but can also feasibly jump to from the low-return independent farming
} 
help more farmers transition from low-return independent, to low-return commercial, and finally to high-return commercial farming, a transition that is especially visible around periods 10-30. However, the prevailing upper Micawber frontier does not change.

Finally, the smallest poverty trap and largest geographic poverty trap occur when both the neighborhood and country-level traps can be overcome (upper right). Here, we see the biggest fall in the prevailing lower Micawber frontier, as trader access and public goods provision allow a wider range of individual TFP values to transition. However, even with both traps able to be overcome, there remains a group of individuals trapped in low-return farming due to their low TFP values. With the potential for taxation, the prevailing upper Micawber frontier shifts right, since again there is a range of farmers for whom the cost of taxes outweigh the benefit from public goods provision.

The geographic poverty trap is the largest when both the meso- and macro-trap can be broken and non-existent when neither can be broken (when only individual characteristics matter in our model). When only the macro-trap is forced, country-level characteristics should not matter but neighborhood-level characteristics that explain the presence of traders still cause considerable overlap. When only the meso-trap is forced, neighborhood-level characteristics should not matter but country-level characteristics that explain taxation and public goods provision still cause considerable overlap. Thus, the degree of overlap suggests that both meso- and macro-variables explain individual-level poverty.

Using our behavioral poverty trap definition based on whether or not farmers engage in low-return farming, overcoming meso- and macro-traps is seen to reduce individual poverty levels. Individuals are least likely to escape poverty when both traps are forced (lower left), where $92 \%$ of individuals still use the low-return technology in period 100 . When both traps can be overcome (upper right), this number falls to $64 \%$. Between these extremes, allowing countries to escape the macro-trap (73\% in lowreturn farming) is better than allowing neighborhoods to escape the meso-trap (77\% in low-return farming).

Furthermore, when taxes arise (right column), the upper Micawber frontier shifts to the right. This result is driven by higher taxes dissuading farmers near the threshold from adopting the high-return technology.

In online appendix, we provide an illuminating period-by-period video that displays movements in the lower and upper Micawber frontiers through time.

\subsection{Case studies: similar individuals in different contexts}

To further highlight these issues, we compare four similar individuals who exist in different neighborhoods and countries in Fig. 10. We focus within the geographic poverty trap, where one's neighborhood and country influence what jobs an individual can pursue and what their income levels become. The individuals we selected have both initial capital and TFP values between 1.1 and 1.11 .

steady state (as seen in the current capital graph when both traps are enforced). Starting in period 7, traders arise whenever the meso-trap can be overcome, with the first traders having the some of the highest TFP levels. 

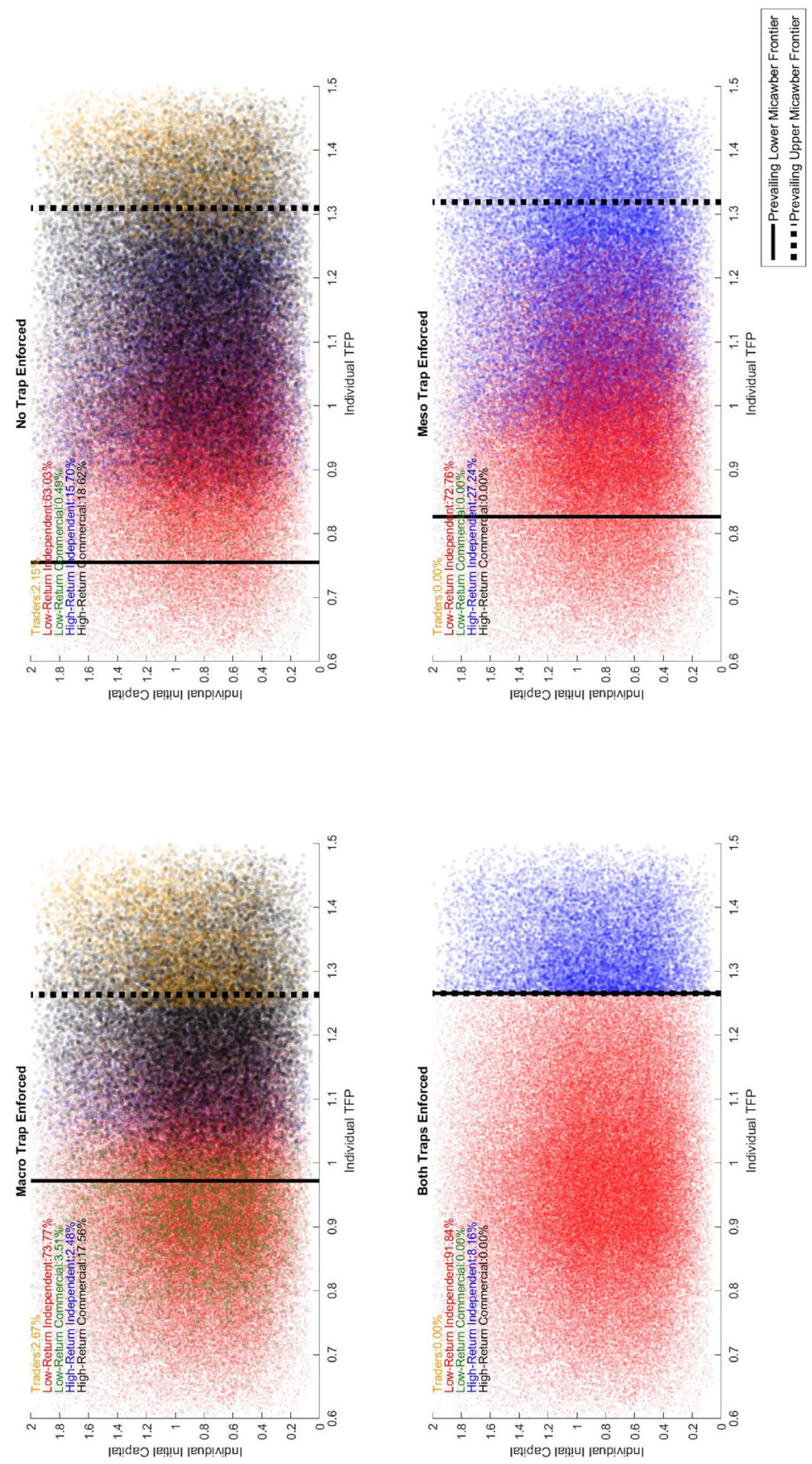

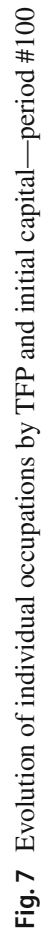




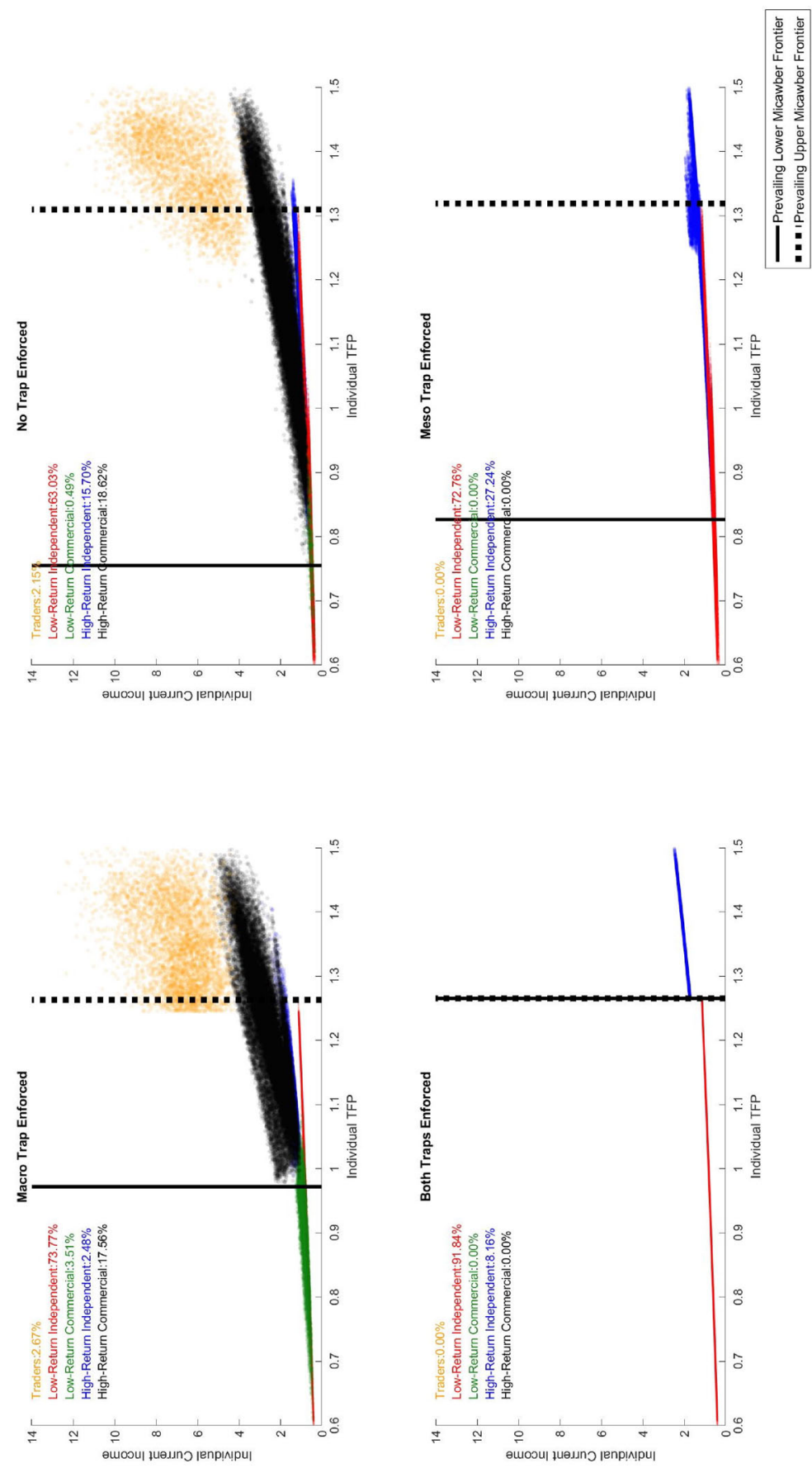

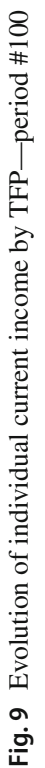


We present graphs of individual income through time in each of the four scenarios, with plots of job type, the fixed cost of the high-return technology, trader access, and trader fees provided in Appendix Figs. 16 through 19. With both traps enforced (bottom left), meso- and macro-context does not matter (since we do not allow for traders or public goods) and every individual reaches the same outcome. Given this TFP level, every individual remains trapped in low-return independent farming and earns an income level of 0.94 . When we allow countries to escape the macro-trap while enforcing the meso-trap (bottom right), taxation increases and farmers now engage in high-return independent farming (though individuals $\mathrm{A}$ and $\mathrm{C}$ jump back and forth due to cycles in $G$ ). While public goods provision facilitates the adoption of the high-return technology and pushes up incomes, the rate of taxation lowers incomes and, in this particular group, these individuals remain about as well of as they would be without taxation (with final incomes ranging from 0.91 to 0.97 ). When we instead allow neighborhoods to produce traders while enforcing the macro-trap (upper left), we see higher incomes with more heterogeneity. Access to traders begins in rounds 10-25 and access to traders helps these individuals transition from low-return independent farming to low-return commercial farming and finally to high-return commercial farming. However, while two individuals (A and D) continue to choose high-return commercial farming (with different incomes resulting from different trader fees), two individuals (B and C) transition to high-return independent farming, since the trader fees grow beyond their willingness to pay. However, comparing their outcomes with the scenario where both traps are enforced, this brief utilization of the trader allows these individuals to transition permanently to high-return independent farming, with incomes about 50\% higher than they would have been without any access to a trader.

Finally, in our baseline scenario both traps can be overcome and we again see different outcomes across these similar individual farmers. For individual D, they reach high-return commercial agriculture as with only the macro-trap enforced. However, they now earn slightly higher incomes as a result of the lower trader fees. For individual $\mathrm{C}$, they also engage in high-return commercial farming and earn a similar income as when only the macro-trap is enforced, though with some cycles resulting from changes in trader fees. Otherwise, individuals A and B perform similarly as when only the meso-trap is enforced, since no traders arise in their neighborhoods.

By focusing on identical individuals in different contexts, we see that one's neighborhood and country matters crucially along with whether or not traps at each level can be overcome. In this example drawn from the geographic poverty trap, individual opportunity is determined by one's context.

\subsection{Summary}

These results further illustrate the importance of one's context in the study of poverty trap models. Our results are consistent with Barrett et al. (2016), who conclude that there is a range of evidence that poverty traps occur in a variety of contexts and include both single and multiple equilibrium traps. These findings also suggest that poverty is likely to be concentrated in regions with little market access and weak governments, a finding consistent with the conclusion made by Kraay and McKenzie (2014). In these 

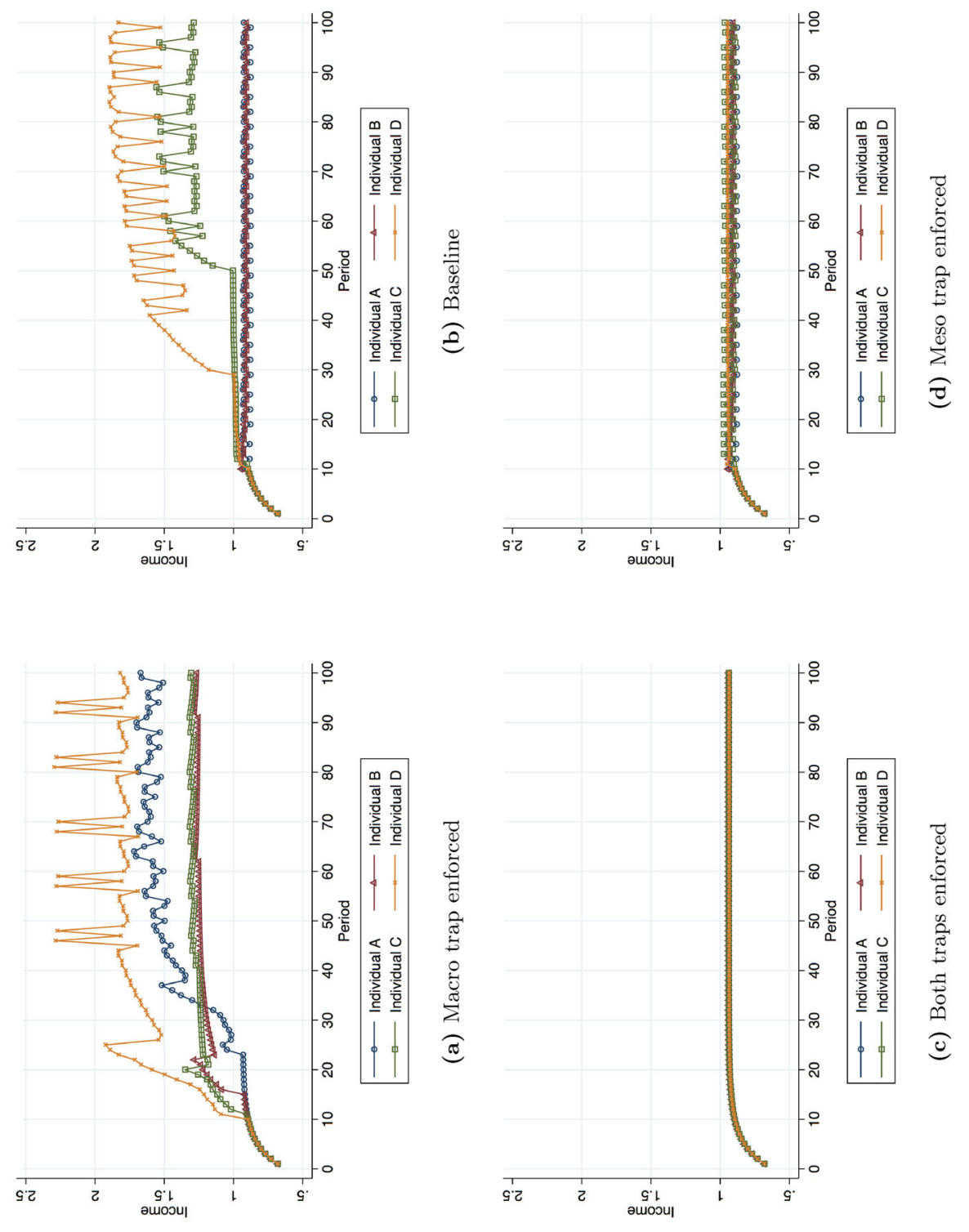
cases, individuals face single equilibrium poverty traps and short-term cash assistance is unlikely to provide long-run benefits. Rather, deeper and more structural reforms are necessary. The baseline model illustrates this, with individual farmers who lack market access and public goods provision face a single equilibrium (or structural) poverty trap, while those fortunate enough to reside where meso- and macro-traps are overcome face a single non-poor equilibrium.

Thus, even if individual TFP cannot be determined easily, targeting policies based on meso- or macro-context may prove more effective. However, these reforms may prove to be the most difficult in isolated regions with weak governments. As seen in our Micawber frontiers above, certain individuals remain trapped in poverty unless policies are able to improve their TFP sufficiently. This implies that single policies will generally prove to be insufficient and that a combination of policies may be required to provide improved public goods, market access, loans to overcome dynamic thresholds, and more productive individual assets.

In related work, we are using this model to answer additional questions. First, we return to the idea that "the absence of evidence is not evidence of absence" and ask whether commonly used empirical tests of poverty traps are likely to find evidence of poverty traps, even when they exist. By using different methods for randomly selecting data from our simulated model, we can evaluate the performance of common empirical methods and the conditions required for them to reliably identify poverty traps accurately. Second, we introduce common policy interventions, such as cash or asset transfers, and evaluate their performance under different contexts.

\section{Conclusions}

This paper develops a fractal poverty trap model that allows us to explore the interactions between micro-, meso-, and macro-poverty traps. Our model is based on forward-looking utility maximizing individuals choosing their occupation and investment levels within endogenously developing markets and national economic policies. By design, our model allows for multiple equilibrium poverty traps at each level of analysis and we generate data with which we evaluate common empirical methods. At both the meso- and macro-levels, we find evidence of divergence, with many blocks and countries trapped in poverty, while others experience sudden surges in growth allowing them to escape to higher income levels. Focusing primarily on the microlevel, we find that individual opportunity depends largely on individual productivity, but also differs greatly based on the meso- and macro-context in which one lives. For those with little access to markets or public goods provision, individuals are likely to remain trapped at low income levels unless they are fortunate enough to have high individual productivity levels. For individuals with intermediate productivity levels, however, moving to a neighborhood with a trader or a country with public goods provision may allow them to transition out of poverty.

These results show that context matters for a large range of individuals in our simulation. A combination of policies is essential to move many of the poor out of poverty traps, including cash transfers but also structural changes promoting greater market access and public goods provision. 
Furthermore, these results highlight the importance of context, but capturing the complexity of context poses a considerable challenge. While we attempted to integrate micro-, meso-, and macro-layers into a fractal poverty trap model as simply as possible, the analysis quickly becomes complex in ways that are hard to quantify empirically. For example, having one rich neighbor might be sufficient for a trader to arise, but their fees depend on neighborhood demand, which is based on a set of TFP levels and growing capital levels that interact in complex ways. At the macro-level, more rich fellow citizens mean that, all else equal, a lower tax rate will suffice for providing a desired level of public goods. However, rich fellow citizens might also vote for lower taxes. This complexity makes fractal poverty traps interesting and important to explore, but it also makes simple narratives challenging. In this paper, we develop a relatively simple fractal poverty trap model and provide a few inferences focused on the complex ways that individual productivity and local and national context interact to determine individual welfare.

Supplementary Information The online version contains supplementary material available at https://doi. org/10.1007/s11403-021-00333-6.

Acknowledgements We are grateful for the suggestions from an anonymous referee, and we also benefitted from feedback from participants at Lafayette College, Davidson College, Lawrence University, the Midwest Economics Association Annual Meeting, and the Eastern Economics Association Meetings.

Author Contributions Both authors contributed to the study conception and design. Model simulations were performed by Shyam Gouri Suresh. Econometric analyses of simulated data were performed by Dylan Fitz. The first draft of the manuscript was written by Dylan Fitz, and both authors commented on previous versions of the manuscript. Both authors read and approved the final manuscript.

Funding Not applicable.

Availability of data and material The simulation code and the datasets generated during and analyzed during the current study are available from the corresponding author on reasonable request.

\section{Declarations}

Conflict of interest The authors declare that they have no conflict of interest.

Code availability The simulation code and the datasets generated and analyzed during the current study are available from the corresponding author on reasonable request.

Ethics approval Not applicable.

Consent to participate Not applicable.

Consent for publication Yes.

Open Access This article is licensed under a Creative Commons Attribution 4.0 International License, which permits use, sharing, adaptation, distribution and reproduction in any medium or format, as long as you give appropriate credit to the original author(s) and the source, provide a link to the Creative Commons licence, and indicate if changes were made. The images or other third party material in this article are included in the article's Creative Commons licence, unless indicated otherwise in a credit line to the material. If material is not included in the article's Creative Commons licence and your intended use is not permitted 
by statutory regulation or exceeds the permitted use, you will need to obtain permission directly from the copyright holder. To view a copy of this licence, visit http://creativecommons.org/licenses/by/4.0/.

\section{Appendix A: Online Videos}

On our websites, we include videos displaying the evolution of our core graphs by period. Specifically, we include full videos for the "Evolution of Individual Occupations by TFP and Initial Capital," "Evolution of Individual Current Capital by TFP," and the "Evolution of Individual Current Income by TFP." These present the full dynamics leading up to the Period \#100 graphs that are included in the paper.

\section{Appendix B: The model}

\section{Grid space and parameterization}

We randomly select a level of TFP $(\alpha)$ and an initial capital level $\left(k_{0}\right)$ for an individual placed in each cell of a 24 by 24 grid. For each country, we choose a minimum individual TFP level between 0.6 and $0.9\left(\alpha_{\min } \sim U[0.6,0.9]\right)$ and a maximum value between 1 and $1.5\left(\alpha_{\max } \sim U[1.0,1.5]\right)$. Within that country, each individual receives a TFP value drawn from a uniform distribution between these values ( $\left.\alpha \sim U\left[\alpha_{\min }, \alpha_{\max }\right]\right)$. Each individual's initial capital level is drawn in a similar manner, with $k_{0 \min } \sim U[0.05,0.50], k_{0 \max } \sim U[1.00,2.00]$, and $k_{0} \sim U\left[k_{0 \min }, k_{0 \max }\right]$. Our numerical simulations are based on the following parameters (Table 2).

\section{Linking overlapping generations model with infinite horizon model}

In this section, we explain how we calibrated $\phi$ in our overlapping generations model in a way that the steady-state capital level is similar in the OLG and infinite horizon models.

Table 2 Parameterization

\begin{tabular}{lll}
\hline Variable & Measure & Values \\
\hline$\phi$ & Discounting of next period income (calibration below) & 0.06 \\
$\rho$ & Rate of time preference & $\frac{1-\beta}{\beta}$ \\
$\alpha$ & Total factor productivity & $\alpha$ between 0.6 and 1.5 \\
$\gamma_{\mathrm{L}}$ & Production exponent for low return technology & 0.3 \\
$\gamma_{\mathrm{H}}$ & Production exponent for high return technology & 0.45 \\
$G$ & Fixed cost of adopting high return agriculture/labor & $G\left(\tau^{*}\right)=\frac{0.45}{1+a R^{* 2}}$ with $a=$ \\
& & 0.00005 \\
$k_{t}$ & Capital & $k_{0}$ between 0.05 and 2 and $k_{t}$ \\
& & grows through time \\
$\theta_{L}, \theta_{H}$ & Depreciation rates & 0.08 \\
$k_{T}$ & Transportation losses & $\theta_{L}=0.55, \theta_{H}=1.0$ \\
\hline
\end{tabular}


Infinite horizon model In the infinite horizon model, an agent maximizes $U=$ $\max \sum_{t=1}^{\infty} \beta^{t-1} u\left(c_{t}\right)$ such that $c_{t} \leq \alpha k_{t}^{\gamma}-G+(1-\delta) k_{t}-k_{t+1}$. Taking the first-order condition with respect to $k_{t+1}$, we have:

$$
\beta^{t} u^{\prime}\left(c_{t}\right)(-1)+\left[\beta^{t+1} u^{\prime}\left(c_{t+1}\right)\left(\alpha \gamma k_{t+1}^{\gamma-1}+(1-\delta)\right)\right]=0
$$

In the steady state, we have that $u^{\prime}\left(c_{t}\right)=u^{\prime}\left(c_{t+1}\right)$ and that $k_{t}=k_{t+1}=k_{t+2}=$ $\cdots=k^{*}$. Adding this to our first-order condition, we have:

$$
\begin{aligned}
& (-1)+\left[\beta\left(\alpha \gamma k^{* \gamma-1}+(1-\delta)\right)\right]=0 \\
& \frac{1}{\beta}+\delta-1=\alpha \gamma k^{* \gamma-1} \\
& k^{*}=\left[\frac{1}{\alpha \gamma}\left(\frac{1}{\beta}+\delta-1\right)\right]^{\frac{1}{\gamma-1}}
\end{aligned}
$$

Overlapping generations model In our overlapping generations model, an agent maximizes $U=\phi \ln \left(c_{t}\right)+(1-\phi) \ln \left(y_{t+1}\right)$ such that $c_{t} \leq \alpha k_{t}^{\gamma}-G+(1-\delta) k_{t}-k_{t+1}$ and $y_{t+1}=\alpha k_{t+1}^{\gamma}-G$. Taking the first-order condition with respect to $k_{t+1}$, we have:

$$
\frac{\phi}{\alpha k_{t}^{\gamma}-G+(1-\delta) k_{t}-k_{t+1}}=\frac{(1-\phi)}{\alpha k_{t+1}^{\gamma}-G}\left(\alpha \gamma k_{t+1}^{\gamma-1}\right)
$$

In the steady state, we have that $k_{t}=k_{t+1}=k_{t+2}=\cdots=k^{*}$. Adding this to our first-order condition, we have:

$$
\frac{\phi}{\alpha k^{* \gamma}-G-\delta k^{*}}=\frac{(1-\phi)}{\alpha k^{* \gamma}-G}\left(\alpha \gamma k^{* \gamma-1}\right)
$$

We first note that there is no closed-from solution for steady-state capital in our OLG model. However, we can express $\phi$ in a way that lets us calibrate our OLG model to the infinite horizon model by parameterizing $\phi$ based on $k^{*}$. Letting $T_{1}=\alpha k^{* \gamma}-G-\delta k^{*}$, $T_{2}=\alpha \gamma k^{* \gamma-1}$, and $T_{3}=\alpha k^{* \gamma}-G$, we have that:

$$
\begin{aligned}
& \frac{\phi}{T_{1}}=\frac{(1-\phi) T_{2}}{T_{3}} \\
& \frac{\phi}{T_{1}}+\frac{\phi T_{2}}{T_{3}}=\frac{T_{2}}{T_{3}} \\
& \phi \frac{T_{3}+T_{1} T_{2}}{T_{1} T_{3}}=\frac{T_{2}}{T_{3}} \\
& \phi=\frac{T_{1} T_{2}}{T_{3}+T_{1} T_{2}}
\end{aligned}
$$

Considering the case where $\beta=0.98$ and $\delta=0.08$ and $\alpha=1$, we present two scenarios, based on individual occupations and potential public goods provision. An 

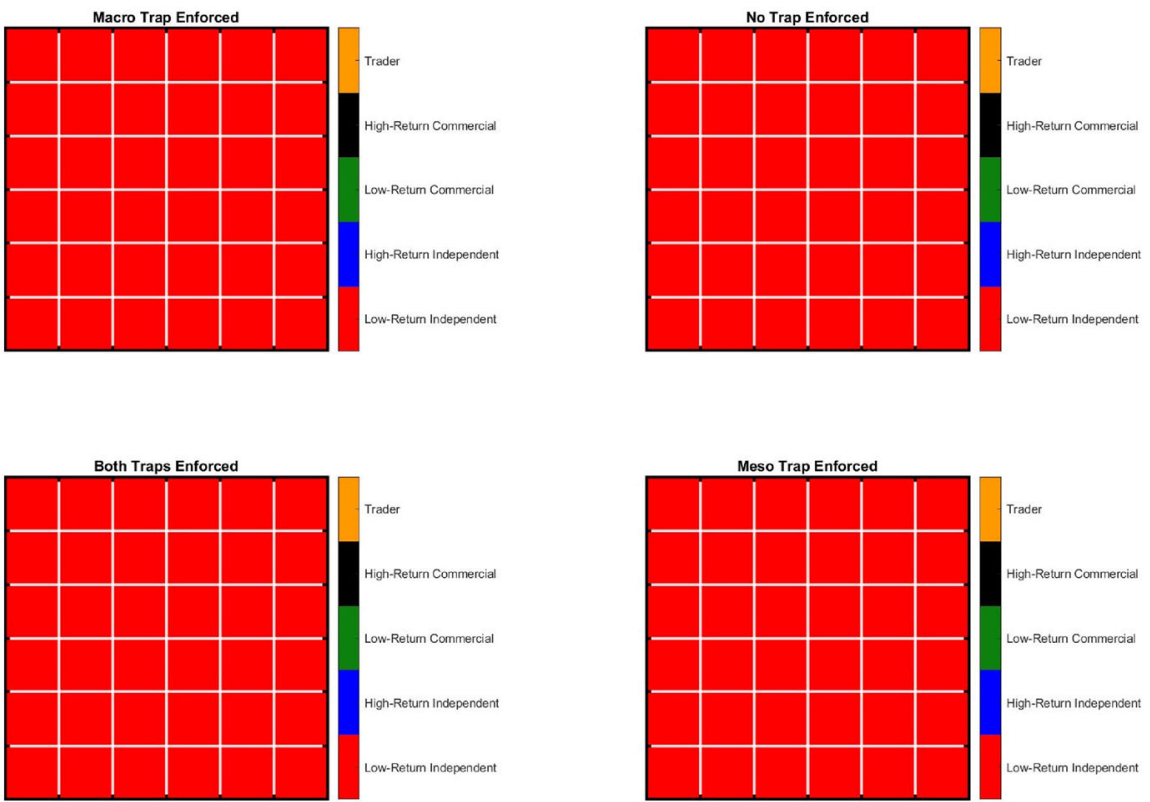

Fig. 11 Displaying occupations by neighborhood for country 9, period \#1

individual using the low-return independent farming with complete public goods provision has:

$$
\begin{aligned}
k^{*} & =\left[\frac{1}{\alpha \gamma}\left(\frac{1}{\beta}+\delta-1\right)\right]^{\frac{1}{\gamma-1}}=\left[\frac{1}{0.3}\left(\frac{1}{0.98}+0.08-1\right)\right]^{\frac{1}{0.3-1}}=4.776 \\
\phi & =\frac{T_{1} T_{2}}{T_{3}+T_{1} T_{2}}=\frac{(1.216)(0.100)}{(1.599)+(1.216)(0.100)}=0.071
\end{aligned}
$$

An individual using the high-return independent farming with no public goods provision has:

$$
\begin{aligned}
k^{*} & =\left[\frac{1}{\alpha \gamma}\left(\frac{1}{\beta}+\delta-1\right)\right]^{\frac{1}{\gamma-1}}=\left[\frac{1}{0.45}\left(\frac{1}{0.98}+0.08-1\right)\right]^{\frac{1}{0.45-1}}=15.291 \\
\phi & =\frac{T_{1} T_{2}}{T_{3}+T_{1} T_{2}}=\frac{(1.739)(0.100)}{(2.962)+(1.739)(0.100)}=0.056
\end{aligned}
$$

Therefore, we choose $\phi=0.06$ as a value that results in steady-state capital levels that are approximately consistent with those from an infinite horizon model under various cases arising within our model. 

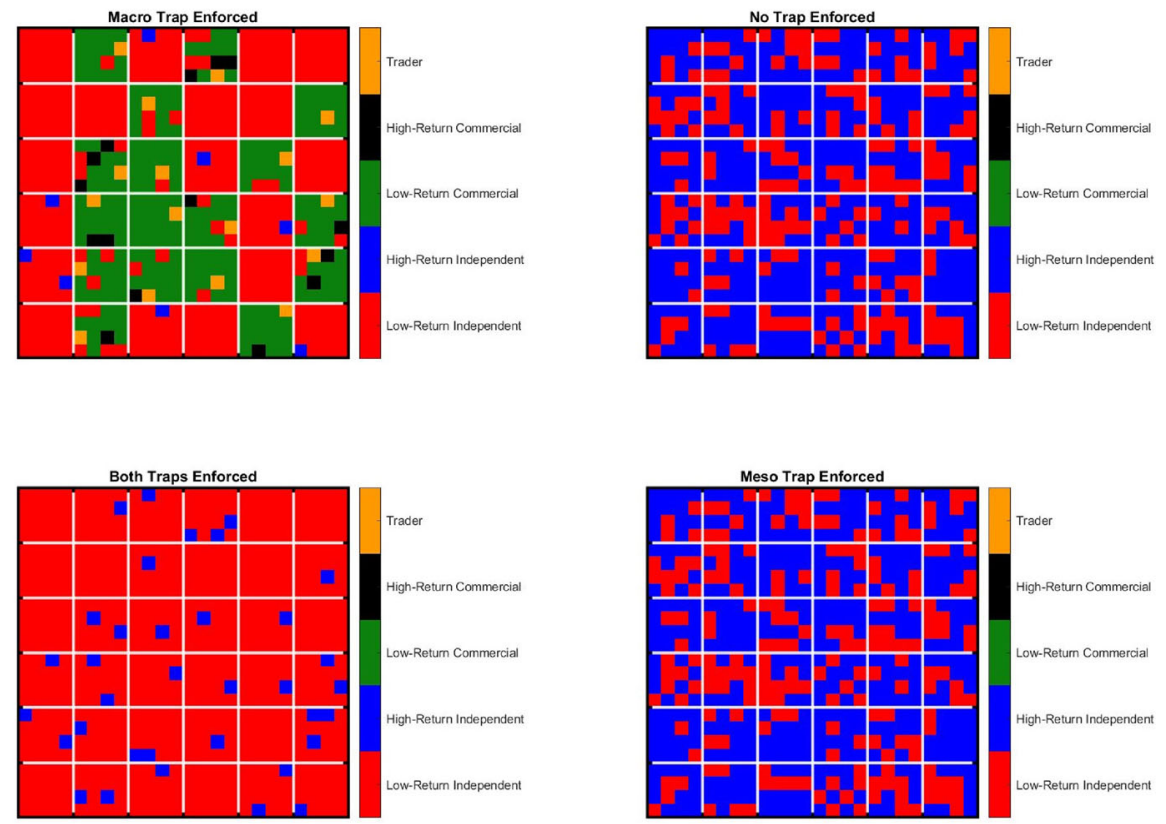

Fig. 12 Displaying occupations by neighborhood for country 9 , period \#10
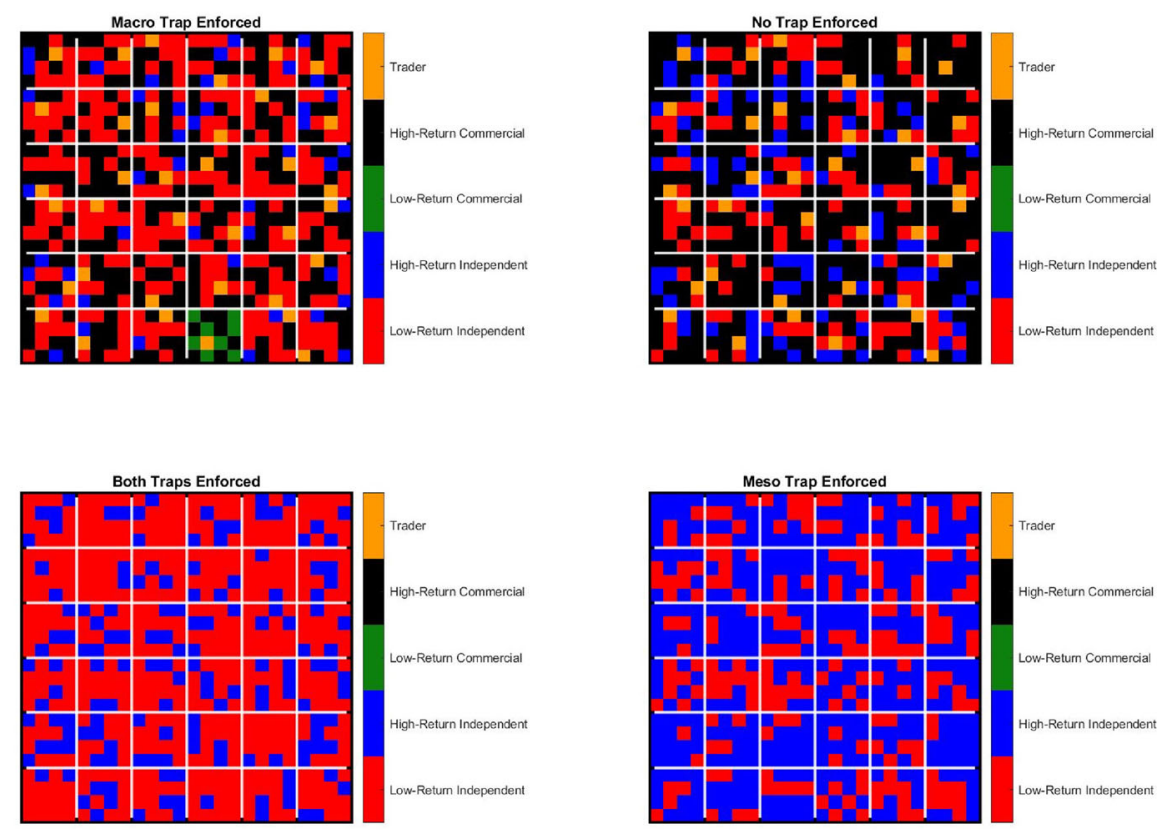

Fig. 13 Displaying occupations by neighborhood for country 9, period \#100 


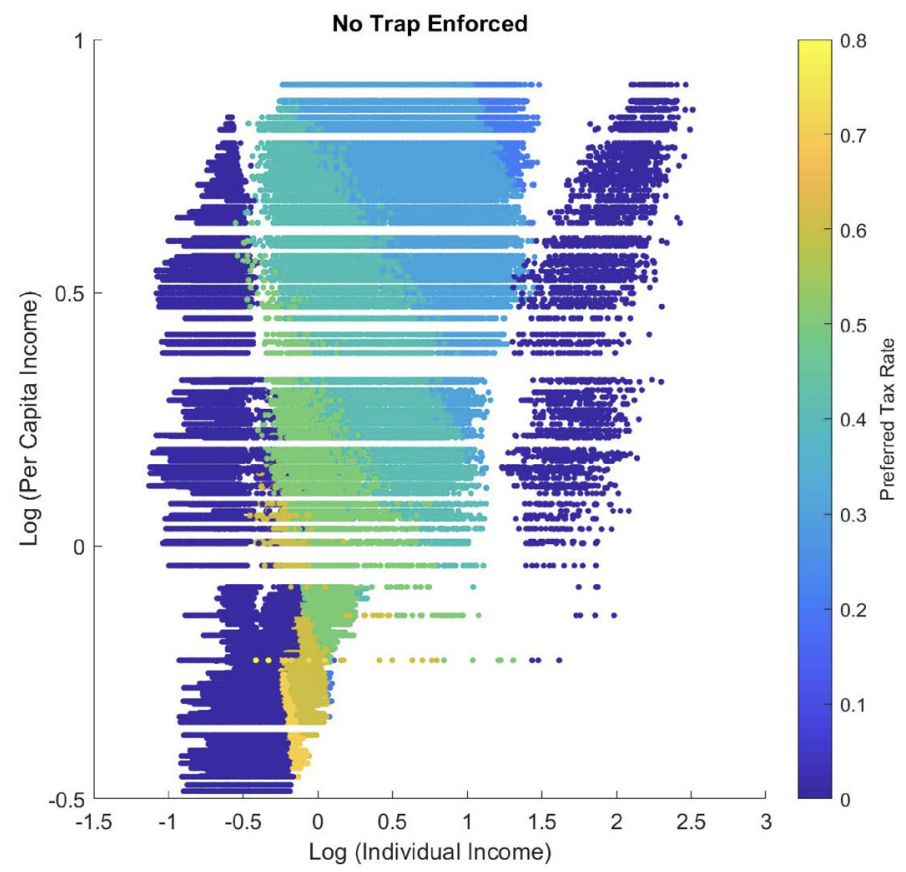

Fig. 14 Preferred tax rates

\section{Sample occupation maps}

Appendix Figs. 11, 12, and 13 present individual occupations for a single country across all four scenarios. Within this single country, each of the 36 sixteen-individual neighborhoods is shown and we present the occupations for periods 1, 10, and 100. Every individual begins in low-return independent farming (red), but through time some individuals move into high-return independent farming (blue), low-return commercial farming (green), high-return commercial farming (black), trading (yellow).

\section{Appendix C: Preferred tax rates}

To highlight the voting behavior driving the macro-level model, it is useful to visually present the preferred tax rates across various scenarios. As discussed in the text, the tax rate that an individual prefers depends on their cost of taxation (a reduction in disposable income) and their benefit from the public goods funded through taxation (a reduction in the fixed cost of the high-return technology). Since the level of public goods provision depends on average income levels (alternatively, we can also consider aggregate income levels), an individual's choice of tax rate depends on their country's average income level. Since the chosen tax rate is based on the median voter, the distribution of income also matters. We highlight these issues in two figures. 


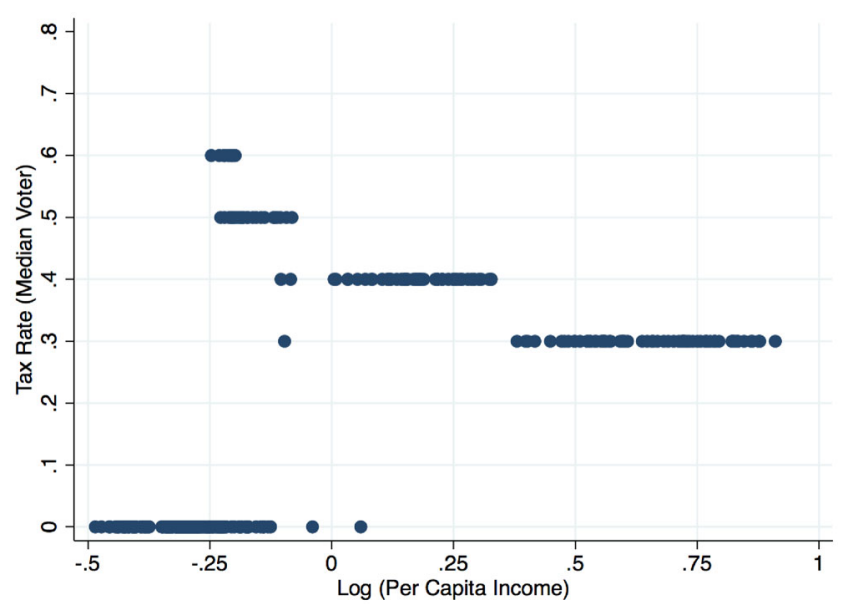

Fig. 15 Tax rate by country-period \#100

First, Appendix Fig. 14 presents preferred individual-level tax rates based on the $\log$ of average income levels within a country (vertical axis) and the log of individual income levels (horizontal axis). Each country can be seen as a horizontal row (at its average income level) that consists of 576 individual dots with color-coded preferred tax rates. The figure is constructed using all individuals from all 300 countries based on the final period of our simulation. Appendix Fig. 14 highlights that preferred tax rates are closely related to individual income levels. Note that extremely poor individuals prefer not to have any taxes, since the reduction in disposable income dominates when an individual is unable to adopt the high-return technology even when the fixed cost is reduced. Traders receive the highest incomes, and they also prefer not to have any taxes, since they do not benefit directly from public goods because they do not pay the fixed cost of the high-return technology. Between these two extremes, farmers may have a range of net benefits from taxation that drive their individual tax preferences. Within this range, the preferred tax rate falls with individual income as the reduction in disposable income matters relatively more at higher individual income levels (thus increasing the cost) and a marginal increase in public goods provision is less likely to determine one's choice of technology (thus decreasing the benefit).

Second, a country's tax rate is chosen by the median voter and we highlight the median voter's preferred tax rate in Appendix Fig. 15. Using only the final period, this figure depicts the chosen tax rate for each country on the vertical axis and the corresponding average income level on the horizontal axis. At the very lowest average income levels, the median voter prefers no taxes and it is only at higher average income levels that taxes appear. Graphing the median voter's preferred tax rate by average income levels reveals this trend, although there is not a one-to-one correspondence due to the complexity of the model, such as the distribution of incomes and access to traders. As discussed in the text of the paper, for example, more unequal countries are likely to choose lower tax rates (since the very poor and very rich prefer lower taxes), while more equal, middle-income societies are more likely to choose higher 

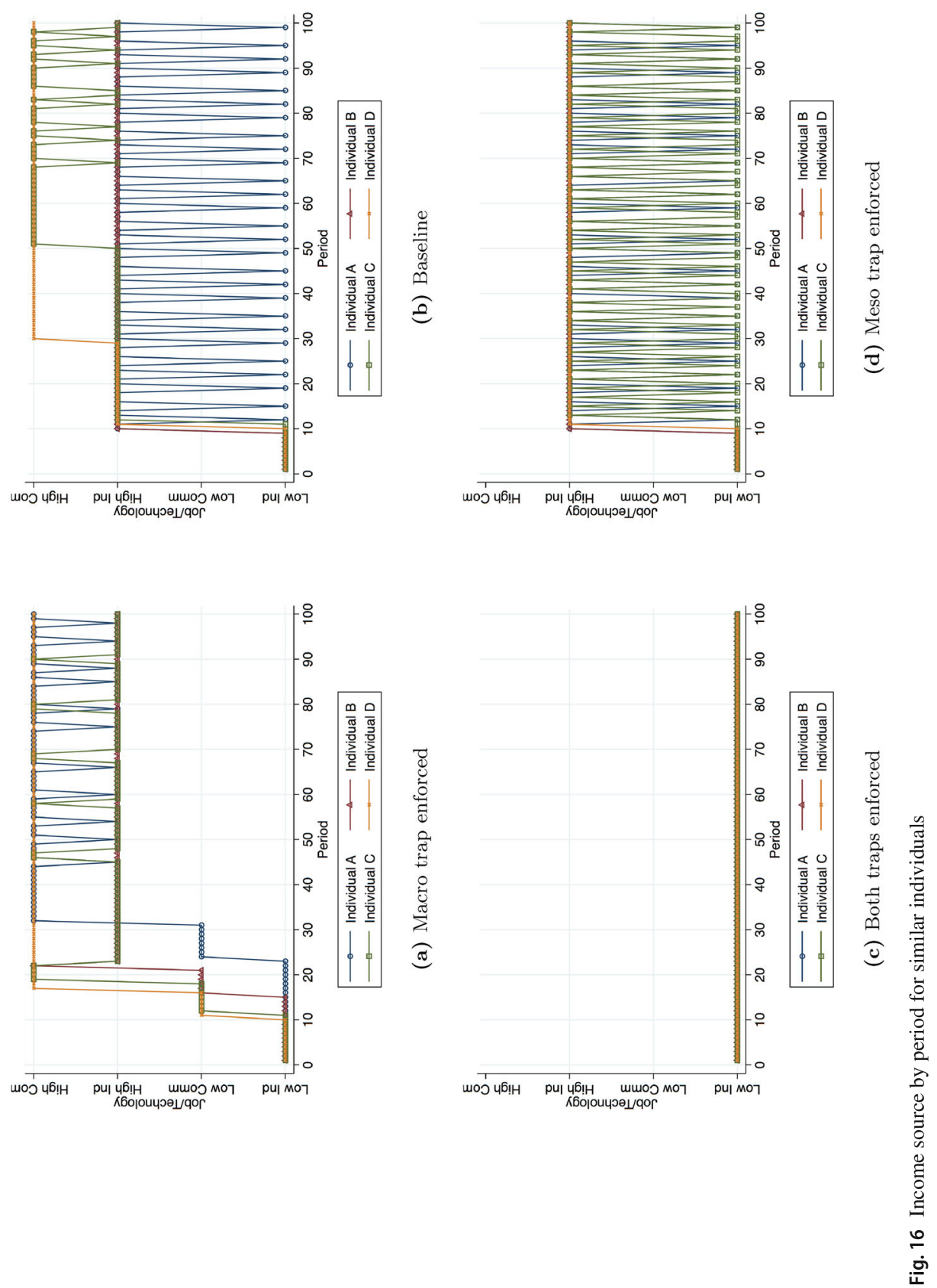

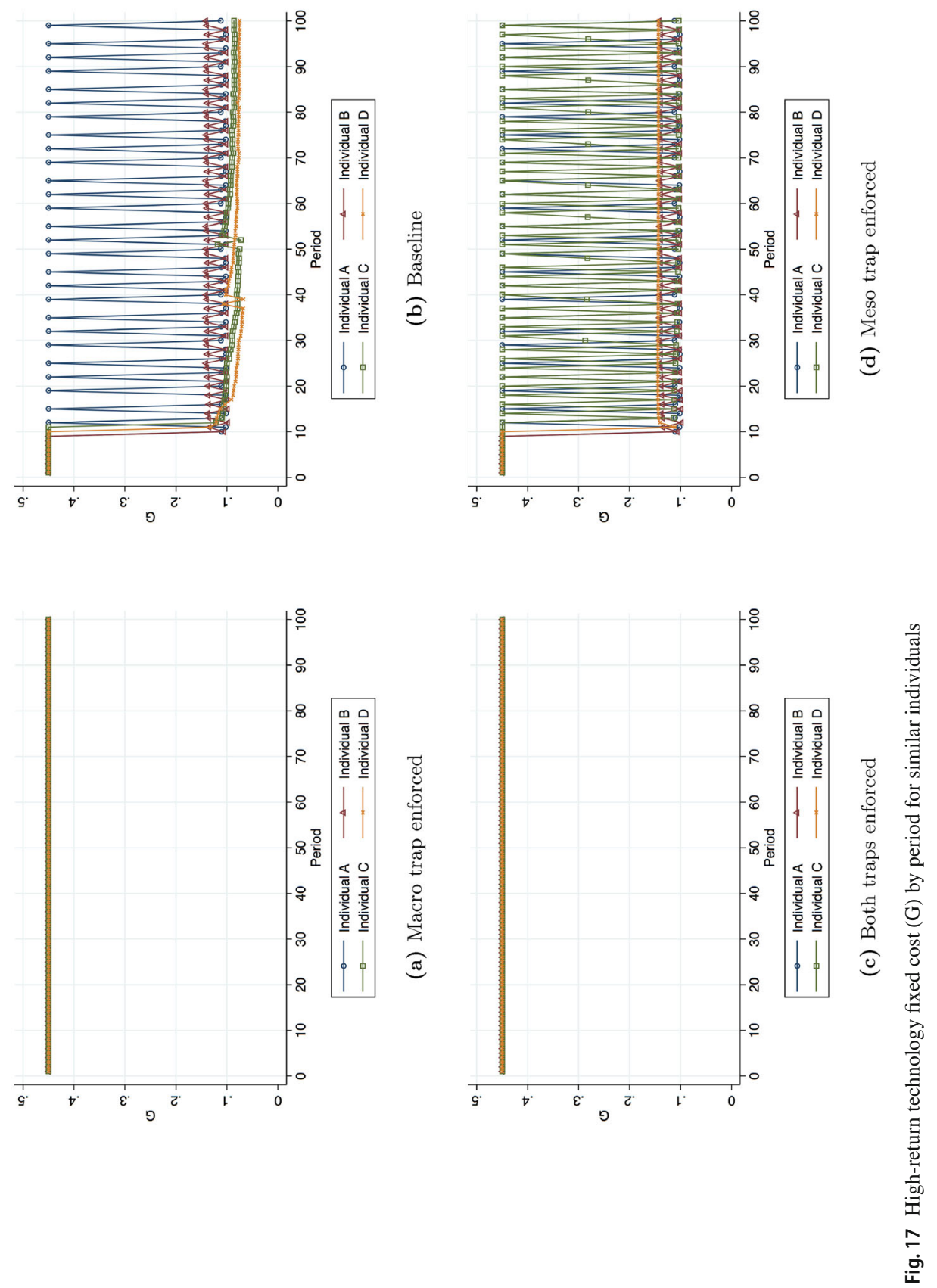

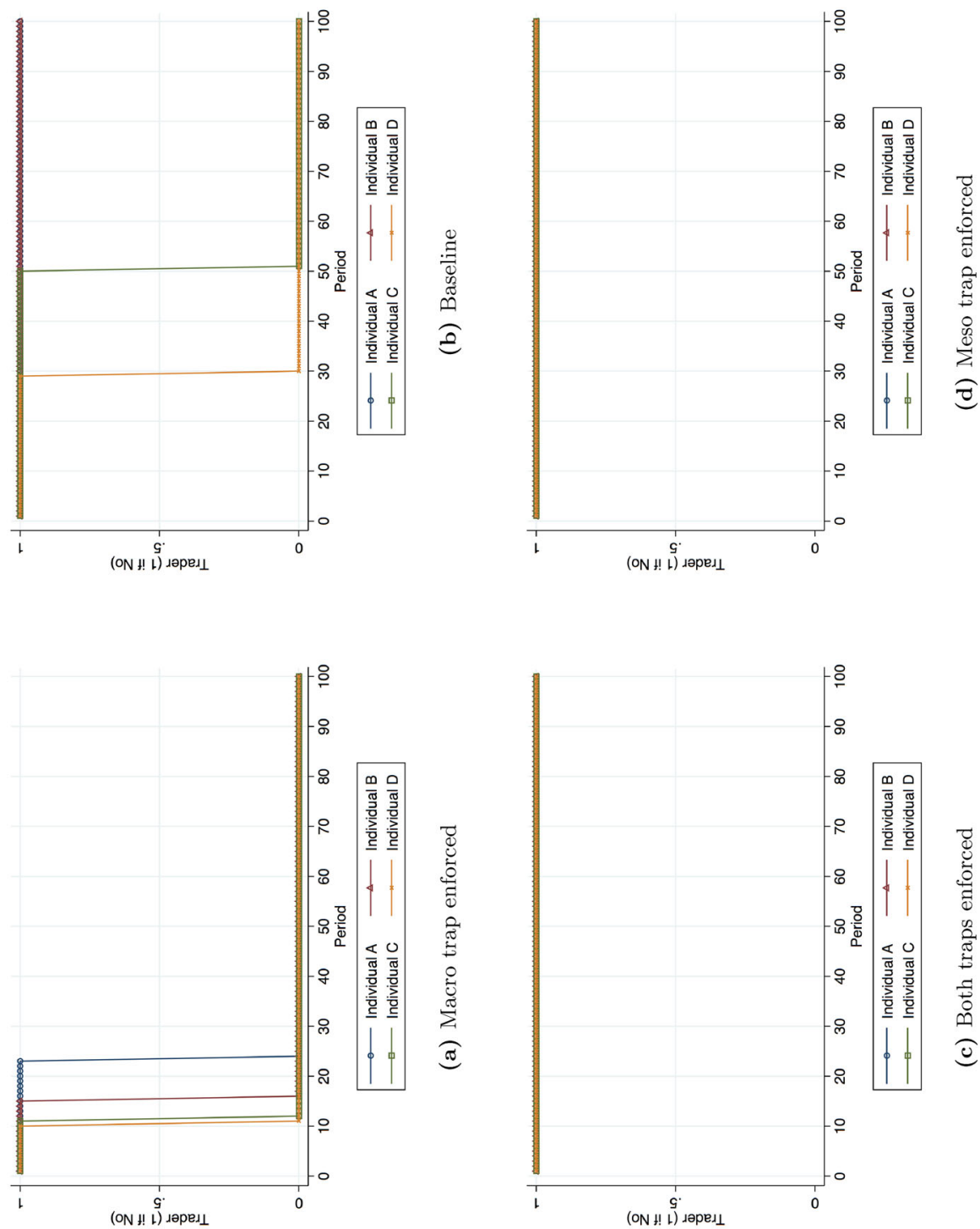

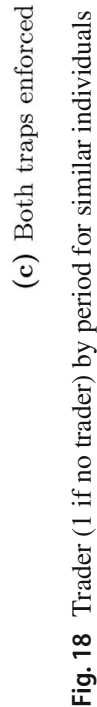



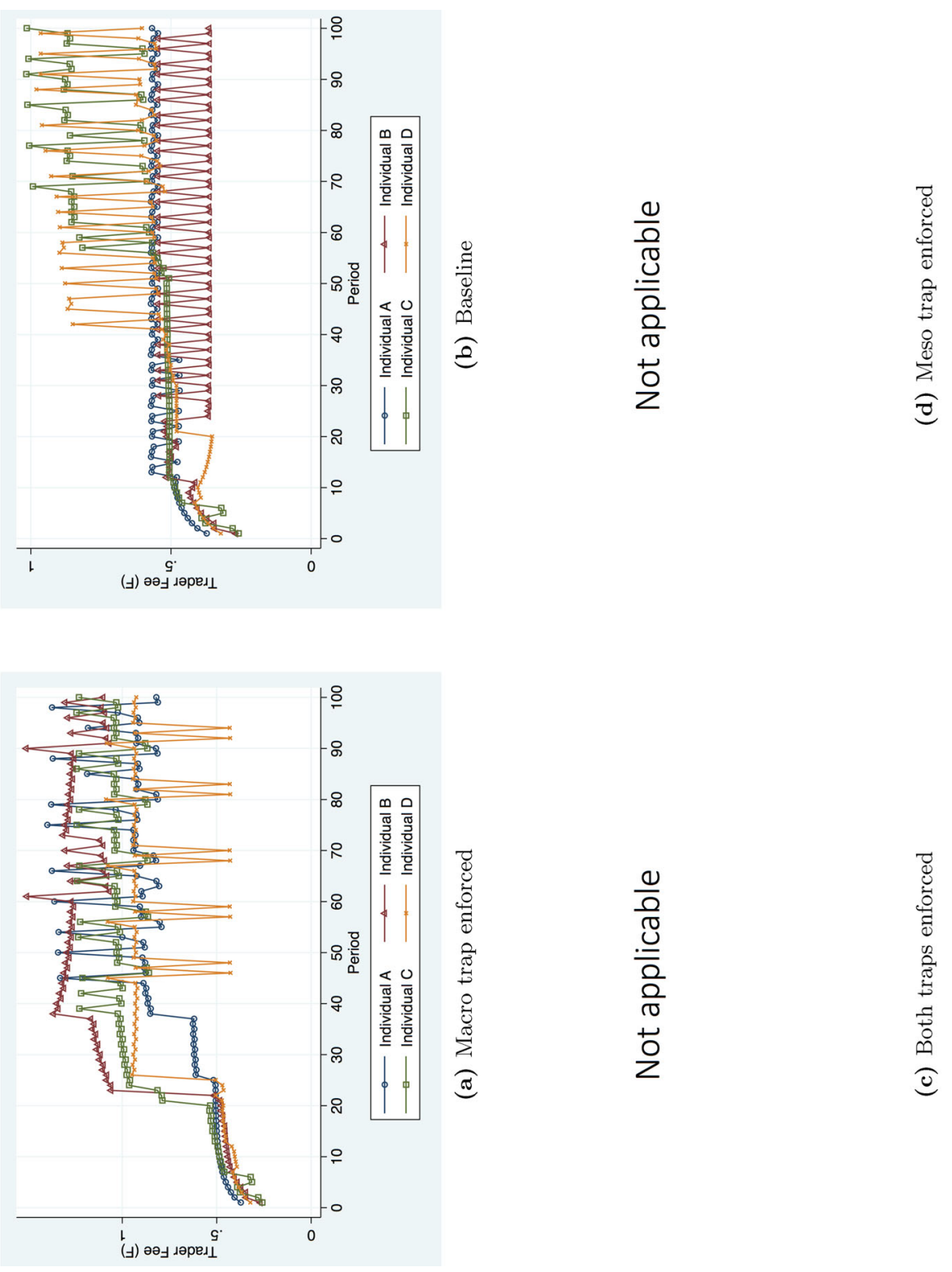

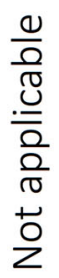


tax rates. Despite this heterogeneity, we generally observe an increase in the chosen tax rate before a gradual decline to a tax rate of 0.3 at higher average income levels. While some individuals do prefer tax rates of 0.7 and 0.8 , these higher rates are not chosen in any of our countries.

Combining these points, we see that some level of equality and a moderate level of overall income will be needed for public goods provision to become feasible.

\section{Appendix D: Similar individuals in different contexts-additional materials}

To complement our graphs of income levels in the text, we additionally display income sources, public goods provision, trader access, and trader fees for the same set of individuals. For income source, 1 is low-return independent farming, 2 is high-return independent farming, 3 is low-return commercial farming, 4 is high-return commercial farming, and 5 is trading (Figs. 16, 17, 18, and 19).

\section{References}

Acemoglu D, Robinson JA (2005) Economic origins of dictatorship and democracy. Cambridge University Press, Cambridge

Acemoglu D, Robinson JA (2013) Why nations fail: the origins of power, prosperity, and poverty. Broadway Business, New York

Acemoglu D, Johnson S, Robinson JA (2001) The colonial origins of comparative development: an empirical investigation. Am Econ Rev 91(5):1369-1401

Acemoglu D, Johnson S, Robinson JA (2005) Institutions as a fundamental cause of long-run growth. In: Aghion P, Durlauf S (eds) Handbook of economic growth, vol 1. Elsevier, Amsterdam, pp 385-472

Adato M, Carter MR, May J (2006) Exploring poverty traps and social exclusion in South Africa using qualitative and quantitative data. J Dev Stud 42(2):226-247

Aghion P, Bolton P (1997) A theory of trickle-down growth and development. Rev Econ Stud 64(2):151-172 Alesina A, Spolaore E (1997) On the number and size of nations. Q J Econ 112(4):1027-1056

Alesina A, Baqir R, Hoxby C (2004) Political jurisdictions in heterogeneous communities. J Polit Econ 112(2):348-396

Anderson JR, Feder G (2004) Agricultural extension: good intentions and hard realities. World Bank Res Obs 19(1):41-60

Arora P, Chong A (2018) Government effectiveness in the provision of public goods: the role of institutional quality. J Appl Econ 21(1):175-196

Azariadis C, Stachurski J (2005) Poverty traps. In: Aghion P, Durlauf S (eds) Handbook of economic growth, vol 1. Elsevier, Amsterdam, pp 295-384

Banerjee AV, Duflo E (2011) Poor economics: a radical rethinking of the way to fight global poverty. Public Affairs

Banerjee AV, Newman AF (1993) Occupational choice and the process of development. J Polit Econ 101(2):274-298

Banerjee A, Breza E, Duflo E, Kinnan C (2019) Can microfinance unlock a poverty trap for some entrepreneurs? Technical report, National Bureau of Economic Research

Barrett CB, Carter MR (2013) The economics of poverty traps and persistent poverty: empirical and policy implications. J Dev Stud 49(7):976-990

Barrett CB, Swallow BM (2006) Fractal poverty traps. World Dev 34(1):1-15

Barrett CB, Marenya PP, McPeak J, Minten B, Murithi F, Oluoch-Kosura W, Place F, Randrianarisoa JC, Rasambainarivo J, Wangila J (2006) Welfare dynamics in rural Kenya and Madagascar. J Dev Stud 42(2):248-277 
Barrett CB, Garg T, McBride L (2016) Well-being dynamics and poverty traps. Annu Rev Resour Econ 8:303-327

Barrett CB, Carter MR, Chavas J-P (2019a) The economics of poverty traps. University of Chicago Press, Chicago

Barrett CB, Carter MR, Chavas J-P (2019b) Introduction. In: Barrett CB, Carter MR, Chavas J-P (eds) The economics of poverty traps. University of Chicago Press, Chicago

Basu K, Van PH (1998) The economics of child labor. Am Econ Rev 88:412-427

Berg CN, Blankespoor B, Selod H (2018) Roads and rural development in Sub-Saharan Africa. J Dev Stud 54(5):856-874

Bowles S, Durlauf SN, Hoff K (2016) Poverty traps. Princeton University Press, Princeton

Carter MR, Barrett CB (2006) The economics of poverty traps and persistent poverty: an asset-based approach. J Dev Stud 42(2):178-199

Carter MR, May J (1999) Poverty, livelihood and class in rural South Africa. World Dev 27(1):1-20

Carter MR, May J (2001) One kind of freedom: poverty dynamics in post-apartheid South Africa. World Dev 29(12):1987-2006

Craft ED (1999) Private weather organizations and the founding of the United States Weather Bureau. J Econ Hist 59(4):1063-1071

Das M (2007) Persistent inequality: an explanation based on limited parental altruism. J Dev Econ 84(1):251-270

Dasgupta P, Debraj R (1986) Inequality as a determinant of malnutrition and unemployment: theory. Econ J 96:1011-1034

Dercon S (1998) Wealth, risk and activity choice: cattle in Western Tanzania. J Dev Econ 55(1):1-42

Easterly W (2006) Reliving the 1950s: the big push, poverty traps, and takeoffs in economic development. J Econ Growth 11(4):289-318

Economist (2018) Extreme poverty is growing rarer: but it is also getting harder to root out. The Economist, September 22

Emerson PM, Souza AP (2003) Is there a child labor trap? Intergenerational persistence of child labor in Brazil. Econ Dev Cult Change 51(2):375-398

Evenson RE (2001) Economic impacts of agricultural research and extension. In: Gardner BL, Rausser GC (eds) Handbook of agricultural economics, vol 1. Elsevier, Amsterdam, pp 573-628

Foster AD, Rosenzweig MR (2010) Microeconomics of technology adoption. Annu Rev Econ 2(1):395-424

Galor O, Zeira J (1993) Income distribution and macroeconomics. Rev Econ Stud 60(1):35-52

Giesbert L, Schindler K (2012) Assets, shocks, and poverty traps in rural Mozambique. World Dev 40(8):1594-1609

Heiner RA (1989) The origin of predictable dynamic behavior. J Econ Behav Organ 12(2):233-257

Huffman WE (2001) Human capital: education and agriculture. In: Gardner BL, Rausser GC (eds) Handbook of agricultural economics, vol 1. Elsevier, Amsterdam, pp 333-381

Ikegami M, Carter MR, Barrett CB, Janzen SA (2019) Poverty traps and the social protection paradox. In: Barrett CB, Carter MR, Chavas J-P (eds) The economics of poverty traps. University of Chicago Press, Chicago

Jalan J, Ravallion M (2002) Geographic poverty traps? A micro model of consumption growth in rural China. J Appl Econom 17(4):329-346

Kraay A, McKenzie D (2014) Do poverty traps exist? Assessing the evidence. J Econ Perspect 28(3):127148

Kwak S, Smith SC (2013) Regional agricultural endowments and shifts of poverty trap equilibria: evidence from Ethiopian panel data. J Dev Stud 49(7):955-975

Lambrecht S, Michel P, Thibault E (2006) Capital accumulation and fiscal policy in an OLG model with family altruism. J Public Econ Theory 8(3):465-486

Lipton M (1994) Growing points in poverty research: labour issues. International Institute for Labour Studies Lybbert TJ, Barrett CB, Desta S, Layne Coppock D (2004) Stochastic wealth dynamics and risk management among a poor population. Econ J 114(498):750-777

McKay A, Perge E (2013) How strong is the evidence for the existence of poverty traps? A multicountry assessment. J Dev Stud 49(7):877-897

Michel P, Thibault E, Vidal J-P (2006) Intergenerational altruism and neoclassical growth models. In: Kolm SC, Ythier JM (eds) Handbook of the economics of giving, altruism and reciprocity, vol 2. Elsevier, Amsterdam, pp 1055-1106 
Miracle MP (1968) Subsistence agriculture: analytical problems and alternative concepts. Am J Agric Econ 50(2):292-310

Murphy KM, Shleifer A, Vishny RW (1989) Industrialization and the big push. J Polit Econ 97(5):10031026

Naschold F (2012) The poor stay poor: household asset poverty traps in rural semi-arid India. World Dev 40(10):2033-2043

Naschold F (2013) Welfare dynamics in Pakistan and Ethiopia-Does the estimation method matter? J Dev Stud 49(7):936-954

Nunn N (2008) The long-term effects of Africas slave trades. Q J Econ 123(1):139-176

Nunn N (2009) The importance of history for economic development. Annu Rev Econ 1(1):65-92

Piketty T, Saez E, Zucman G (2017) Distributional national accounts: methods and estimates for the United States. Q J Econ 133(2):553-609

Quah DT (1996) Twin peaks: growth and convergence in models of distribution dynamics. Econ J 106(437):1045-1055

Quah DT (1997) Empirics for growth and distribution: stratification, polarization, and convergence clubs. J Econ Growth 2(1):27-59

Quisumbing AR, Baulch B (2013) Assets and poverty traps in rural Bangladesh. J Dev Stud 49(7):898-916

Rosenstein-Rodan PN (1943) Problems of industrialisation of eastern and south-eastern Europe. Econ J 53(210/211):202-211

Rosenzweig MR, Udry CR (2019) Assessing the benefits of long-run weather forecasting for the rural poor: farmer investments and worker migration in a dynamic equilibrium model. Technical report, National Bureau of Economic Research

Rosser JB (1997) Chaos theory and rationality in economics. In: Kiel LD, Elliott E (eds) Chaos theory in the social sciences. University of Michigan Press, Ann Arbor, pp 199-213

Rosser JB (1999) On the complexities of complex economic dynamics. J Econ Perspect 13(4):169-192

Sachs J (2006) The end of poverty: economic possibilities for our time. Penguin, New York

Sachs J, Malaney P (2002) The economic and social burden of malaria. Nature 415(6872):680-685

Stifel D, Minten B (2017) Market access, well-being, and nutrition: evidence from Ethiopia. World Dev 90:229-241

Stifel D, Minten B, Koru B (2016) Economic benefits of rural feeder roads: evidence from Ethiopia. J Dev Stud 52(9):1335-1356

Stiglitz JE (2015) Devolution, independence, and the optimal provision of public goods. Econ Transp 4(1-2):82-94

Zimmerman FJ, Carter MR (2003) Asset smoothing, consumption smoothing and the reproduction of inequality under risk and subsistence constraints. J Dev Econ 71(2):233-260

Publisher's Note Springer Nature remains neutral with regard to jurisdictional claims in published maps and institutional affiliations. 